\title{
MIGRAÇÕES CLIMÁTICAS E CIDADES RESILIENTES: UMA NOVA AGENDA URBANA PARA O DESENVOLVIMENTO SUSTENTÁVEL
}

\section{CLIMATE MIGRATION AND RESILIENT CITIES: A NEW URBAN AGENDA FOR SUSTAINABLE DEVELOPMENT}

\author{
Heline Sivini Ferreira ${ }^{1}$ \\ Nicholas Robinson ${ }^{2}$ \\ Diogo Andreola Serraglio ${ }^{3}$
}

RESUMO: Tendo em vista que centros urbanos podem estimular o recebimento de migrantes ambientais, o presente estudo almeja examinar como a mobilidade humana decorrente dos efeitos adversos da mudança climática pode favorecer a expansão equilibrada de cidades, de modo a proporcionar o resguardo da dignidade da pessoa humana. Para tanto, por meio do método dedutivo, pretende-se alcançar os seguintes objetivos específicos: inicialmente, a análise de como

\footnotetext{
${ }^{1}$ Doutora em Direito pela Universidade Federal de Santa Catarina (UFSC), tendo realizado seu estágio de doutoramento no Centre for Environmental Law, da Macquarie University, em Sidney, Austrália. Mestre em Direito pela UFSC. Graduada em Direito pela Universidade Estadual da Paraíba (UEPB). Professora Adjunta do Curso de Graduação e do Programa de Pós-Graduação em Direito da Pontifícia Universidade Católica do Paraná (PUCPR). Pesquisadora do Grupo de Pesquisa Direito Ambiental e Ecologia Política na Sociedade de Risco (UFSC) e do Grupo de Pesquisa Meio Ambiente: Sociedades Tradicionais e Sociedade Hegemônica (PUCPR). Diretora de Assuntos Internacionais do Instituto O Direito por um Planeta Verde (IDPV). Coordenadora Regional da Associação dos Professores de Direito Ambiental do Brasil (APRODAB-Sul). Membro da Commission on Environmental Law da International Union for Conservation of Nature (IUCN). Curitiba, Paraná, Brasil. E-mail: hsivini@yahoo.com.br

${ }^{2}$ Doutor em Direito pela Columbia University School of Law. Graduado em Direito pela Brown University. Professor Emérito da Elisabeth Haub School of Law da Pace University, tendo sido responsável pela formulação e implementação do programa de Direito Ambiental da Pace University. Presidente-fundador da International Union for Conservation of Nature (IUCN) e ex-presidente da Comissão Mundial de Direito Ambiental da IUCN. Participou dos travaux préparatoires que resultaram na Conferência das Nações Unidas sobre o Meio Ambiente e Desenvolvimento de 1992 e na Agenda 21. Atualmente, coordenador executivo do International Council of Environmental Law. E-mail: nrobinson@pace.law.edu.

${ }^{3}$ Doutorando em Direito pela Pontifícia Universidade Católica do Paraná (PUCPR), tendo realizado seu estágio de doutoramento na Elisabeth Haub School of Law da Pace University por intermédio de bolsa da Comissão Fulbright e na United Nations University - Environment and Human Security (UNU-EHS). Bolsista da Coordenação de Aperfeiçoamento de Pessoal de Nível Superior (CAPES). Mestre em Direito pela PUCPR. Especialista em Direito Internacional do Meio Ambiente pela United Nations Institute for Training and Research (UNITAR). Especialista em Direito Ambiental pela Universidade Federal do Paraná (UFPR). Graduado em Direito pelo Centro Universitário Curitiba (UNICURITIBA). Membro da Comissão Mundial de Direito Ambiental da International Union for Conservation of Nature (IUCN) e da Rede Sul Americana para as Migrações Ambientais (RESAMA). Advogado. Curitiba, Paraná, Brasil. E-mail: diogo.aserraglio@gmail.com
} 
as alterações induzidas do clima provocam o deslocamento forçado de pessoas, bem como os delineamentos que possibilitam a identificação deste grupo de indivíduos; posteriormente, a investigação de como centros urbanos lidam com as consequências de ambos os fenômenos e; por fim, o estudo da Agenda 2030 para o Desenvolvimento Sustentável, com especial enfoque no Objetivo do Desenvolvimento Sustentável 11 (ODS 11), que apesar de almejar tornar as cidades e assentamentos urbanos inclusivos, seguros, resilientes e sustentáveis, não leva em consideração a relevância dos processos migratórios forçados nesse processo. Explora-se, diante disso, a Nova Agenda Urbana (2016), elaborada pelo Programa das Nações Unidas para os Assentamentos Humanos (ONU-Habitat). Embora o movimento populacional para os centros urbanos revele uma variedade de obstáculos, reconhece-se que a migração ambiental pode trazer significativa contribuição social, econômica e cultural para a vida urbana.

PALAVRAS-CHAVE: Mudanças climáticas; Migração climática; Cidades resilientes; Desenvolvimento Sustentável; Nova Agenda Urbana.

ABSTRACT: Given that urban centers can stimulate the reception of environmental migrants, this study aims to examine how human mobility due to the adverse effects of climate change can contribute to the sustainable expansion of cities, promoting the protection and respect of the human dignity. Through the deductive method, it is intended to achieve the following specific objectives: initially, analyze how climate change triggers displacements, as well as the parameters that allow the identification of this group of people; later, examine the consequences of both phenomena to cities and; finally, look into the Agenda 2030 for Sustainable Development, with special emphasis on the Sustainable Development Goal 11 (SDG 11). Despite the intent to make cities and human settlements inclusive, safe, resilient and sustainable, it does not take into account the relevance of forced migration in this process. Therefore, the New Urban Agenda (2016), developed by the United Nations Human Settlements Programme (UN-Habitat), is considered: although the population movement towards urban centers reveals a variety of challenges, it recognizes that environmental migration can bring significant social, economic and cultural contribution to urban life.

KEYWORDS: Climate change; Climate migration; Resilient cities; Sustainable Development; New Urban Agenda. 
INTRODUÇÃO

Processos migratórios forçados têm se intensificado em razão dos efeitos adversos das mudanças climáticas no decorrer das últimas décadas. A elevação do nível do mar, secas e processos de desertificação, bem como a maior incidência de eventos climáticos extremos figuram como algumas das causas que propiciam o deslocamento interno e/ou transfronteiriço de milhares de pessoas para grandes centros urbanos, desafiando a governança de diversos países em desenvolvimento.

Considerando que a população urbana global aumentou de 746 milhões para 7,6 bilhões entre 1950 e 2017, e diante da estimativa de que mais 03 bilhões de pessoas viverão em áreas urbanizadas até 2050, preocupa-se com o crescimento desordenado e a capacidade de manter cidades funcionando de modo sustentável.

Assim sendo, dado que cidades podem figurar como arquitetas de políticas de acolhimento e inclusão de migrantes ambientais, pretende-se analisar como a mobilidade humana decorrente dos efeitos adversos das mudanças climáticas pode contribuir para a expansão sustentável de centros urbanos, de modo a promover o resguardo da dignidade da pessoa humana.

Por meio do método dedutivo, inicialmente se examina como as alterações do clima implicam o deslocamento forçado de pessoas, bem como os delineamentos que permitem a identificação desta categoria de pessoas. Em seguida, a repercussão desse fenômeno sobre os centros urbanos é investigada: ao mesmo tempo em que são responsáveis pela emissão de gases de efeito estufa (GEE) na atmosfera, cidades tornam-se cada vez mais suscetíveis e incapazes de lidar com as suas consequências.

Parte-se, então, para o estudo da Agenda 2030 para o Desenvolvimento Sustentável e, mais precisamente, do Objetivo de Desenvolvimento Sustentável 11 (ODS 11), o qual, apesar de almejar tornar as cidades e assentamentos urbanos inclusivos, seguros, resilientes e sustentáveis, não leva em consideração a relevância dos processos migratórios forçados nesse processo. Sugere-se, diante disso, novas abordagens que discutam as distintas necessidades dos migrantes ambientais.

Refletindo essa realidade, explora-se, por fim, a Nova Agenda Urbana (2016), elaborada pelo Programa das Nações Unidas para os Assentamentos Humanos (ONU-Habitat). Embora o movimento populacional para os centros urbanos revele uma variedade de obstáculos, reconhece-se que a migração ambiental pode trazer significante contribuição social, econômica e cultural para a vida urbana. 


\section{A INTENSIFICAÇÃO DOS PROCESSOS MIGRATÓRIOS EM RAZÃO DAS MUDANÇAS CLIMÁTICAS}

As questões que envolvem as mudanças climáticas ${ }^{4}$ mostram-se como uma das mais debatidas deste século. Esse fenômeno foi acelerado em razão da emissão desenfreada de GEE na atmosfera pelas ações antropogênicas em busca do crescimento econômico (BRADBROOK, OTTINGER. 2003, p. 13-14). Nessa perspectiva, Leal-Arcas (2013, p. 28) destaca que o aquecimento da superfície terrestre ameaça não apenas a humanidade, mas também a sustentabilidade do meio ambiente. Trata-se, pois, de uma questão global que trará impactos substanciais aos sistemas social, econômico e ambiental, como se verifica abaixo:

[...] a média mundial de desastres naturais subiu de 260 em 1990 para 337 em 2003, e o número de pessoas atingidas por esses desastres cresceu exponencialmente. É certo que a Terra tem passado, ao longo de toda a sua história geológica, por enormes variações climáticas. No entanto, há evidências cada vez mais fortes de que as mudanças mais recentes não são variações naturais, mas estão relacionadas com um aumento na temperatura na Terra [...] (JURAS, 2008, p. 35).

O Quinto Relatório de Avaliação (AR5) do Painel Intergovernamental sobre as Mudanças Climáticas (IPCC), publicado em 2014, acentua que as atividades humanas alteraram e continuam a alterar a composição atmosférica da superfície da Terra (IPCC, 2013, p. 18). É, portanto, incontroverso que houve uma elevação da temperatura média global no período compreendido entre os anos de 1951 e 2010. Nesse cenário, a emissão de GEE desponta como a principal causa do aquecimento da superfície terrestre, cuja temperatura aumentou, nesse intervalo de tempo, entre 0.5 C e 1.3 C. Ademais, a média anual do aquecimento terrestre, constatada a partir do século XX, propiciou a inversão da tendência de resfriamento a longo prazo dos últimos 5.000 anos nas altas latitudes do hemisfério norte. Isto é, no tocante às temperaturas médias anuais desse hemisfério, o período compreendido entre os anos de 1983 a 2012 foi, muito provavelmente, o que teve os 30 anos mais quentes dos últimos 1.400 anos (IPCC, 2013, p. 25-16).

Para que a temperatura média do globo não ultrapasse 2 ㅇ C em relação aos índices constatados no início do processo de industrialização, a concentração de dióxido de carbono $\left(\mathrm{CO}_{2}\right)$ na atmosfera não poderá exceder 550 partes por milhão em volume (ppmv) (JURAS, 2008, p. 15).

\footnotetext{
${ }^{4}$ De acordo com a Convenção-Quadro das Nações Unidas sobre Mudança do Clima (CONUMC), ratificada em 1992, mudanças do clima significa "uma mudança de clima que possa ser direta ou indiretamente atribuída à atividade humana que altere a composição da atmosfera mundial e que se some àquela provocada pela variabilidade climática natural observada ao longo de períodos comparáveis" (ONU, 1992).
} 
Nesse sentido, o AR5 apontou que o aumento da concentração de $\mathrm{CO}_{2}$ na atmosfera subiu de 278 ppmv, em 1750, para 390.5 ppmv, em 2011, tendo a quantidade desse composto químico aumentado 4.0 pentagramas de Carbono por ano $(\mathrm{PgC} / \mathrm{ano})^{5}$ na primeira década do século XXI (IPCC, 2013, p. 05).

Em outubro de 2018, o IPCC disponibilizou a versão final do relatório especial intitulado Aquecimento Global de $1,5^{\circ} \mathrm{C}(\mathrm{SR} 15)^{6}$, o qual examina os caminhos disponíveis para limitar o aumento da temperatura terrestre em $1,5^{\circ} \mathrm{C}$ em relação aos níveis pré-industriais, o que seria necessário para evitá-lo e suas respectivas consequências ${ }^{7}$. Além de confirmar que as emissões antrópicas já causaram a elevação da temperatura em $1,0^{\circ} \mathrm{C}$ e que suas consequências continuarão alterando o sistema climático por séculos a milênios, o documento destaca que o aquecimento da superfície do planeta deverá atingir 1,50 C entre 2030 e 2052 se os índices atuais de lançamento de GEE na atmosfera permanecerem inalterados (IPCC, 2018, p. 04).

Enquanto o AR5 projetou a intensificação do deslocamento de pessoas em razão das mudanças climáticas ${ }^{8}$, sobretudo daquelas que carecem de recursos e que se encontram expostas a eventos climáticos extremos em países em desenvolvimento, o SR15 salienta que aspectos ambientais, econômicos e sociais subjacentes à migração são complexos e variados, o que torna a avaliação do seu nexo de causalidade com os efeitos da mudança climática um desafio. Aponta, ainda, que raramente existe um único motivo para a mobilidade humana: trabalho, educação, qualidade de vida, laços familiares, acesso a recursos, grau de desenvolvimento e, dependendo da

\footnotetext{
${ }^{5}$ Tenha-se presente que $01 \mathrm{PgC}$ (um pentagrama de Carbono) equivale a $10^{15} \mathrm{~g}$ ou a um bilhão de toneladas de Carbono.

${ }^{6} \mathrm{O}$ título completo do estudo é Aquecimento Global de $1,5^{\circ} \mathrm{C}$ : relatório especial do IPCC sobre os impactos do aquecimento global de $1,5^{\circ} \mathrm{C}$ acima dos níveis pré-industriais e das vias de emissão de gases de efeito estufa no contexto de fortalecimento da resposta global à ameaça da mudança climática, desenvolvimento sustentável e esforços para erradicar a pobreza. No original, do inglês, Global Warming of $1,5^{\circ} \mathrm{C}$ : an IPCC special report on the impacts of global warming of $1,5^{\circ} \mathrm{C}$ above pre-industrial levels and related global greenhouse gas emission pathways, in the context of strengthening the global response to the threat of climate change, sustainable development, and efforts to eradicate poverty.

${ }^{7}$ Em verdade, o estudo simula cenários relacionados aos impactos da mudança climática que poderiam ser evitados com a limitação do aquecimento global em $1,5^{\circ} \mathrm{C}$ em comparação com $2^{\circ} \mathrm{C}$ ou mais. Até 2100 , a diferença de $0,5^{\circ} \mathrm{C}$ reduziria a elevação média do nível do mar em 10 centímetros $(\mathrm{cm})$. Da mesma forma, o degelo total do Oceano Ártico no verão aconteceria apenas uma vez por século, ao invés de pelo menos uma vez por década. Ainda, enquanto o aumento de $1,5^{\circ} \mathrm{C}$ provocaria a redução de 70 a $90 \%$ dos recifes de corais existentes, a elevação de $2^{\circ} \mathrm{C}$ acarretaria o seu desaparecimento total. O IPCC conclui que tal diferença não só diminuiria os efeitos adversos da alteração do clima, mas também traria benefícios evidentes para a população e para os ecossistemas terrestres (IPCC, 2018, p. 04)

${ }^{8}$ O Primeiro Relatório de Avaliação (AR1) do Painel Intergovernamental sobre as Mudanças Climáticas (IPCC), publicado em 1990, já abordava a questão, nos seguintes termos: "[...] um dos efeitos mais graves da mudança climática pode ser a migração forçada de milhões de pessoas em razão da erosão e de inundações costeiras, assim como de secas severas" (IPCC, 1990, p. 103).
} 
situação, condições ambientais ou climáticas, são fatores que podem ser levados em consideração (IPCC, 2018, p. 116).

Deste modo, a sobrecarga ocasionada pelo constante aumento da poluição atmosférica tem acarretado resultados negativos sobre o meio ambiente, trazendo em pauta novos problemas para a comunidade internacional, como a necessidade de se regulamentar a situação daqueles que se veem obrigados a migrar em decorrência dos efeitos adversos das mudanças climáticas.

A mobilidade humana em razão de infortúnios ambientais não é um fato inédito na história da humanidade. A devastação do meio ambiente e a incidência de desastres naturais, associadas a um quadro de pobreza, insegurança alimentar e conflitos sociais, sempre ameaçaram a sobrevivência do homem e propiciaram a migração de diversos aglomerados humanos (RAMOS, 2015 , p. 739). Myers (1995, p. 20) assinala que, em 1995, o número total de seres humanos deslocados pela degradação ambiental no globo somava pelo menos 25 milhões de pessoas, ao passo que os chamados refugiados tradicionais ${ }^{9}$, no mesmo ano, totalizavam não mais que 27 milhões de indivíduos. O autor aponta ainda que a situação daqueles forçados a migrar por conta de adversidades ambientais pode

[...] tornar-se uma das principais crises de todos os tempos. Por um longo período, a questão foi vista como uma preocupação periférica, isto é, uma espécie de aberração dentro da ordem normal das coisas. Em um futuro próximo, entretanto, essa categoria de pessoas tende a caracterizar a paisagem terrestre. Trata-se de um fenômeno que trará profundas mudanças, as quais serão marcadas, frequentemente, por privação extrema, medo e desespero $\left(1995\right.$, p. 20) ${ }^{10}$.

No que tange às mudanças climáticas ${ }^{11}$, calcula-se que o número de pessoas removidas visando escapar das consequências das alterações do clima, como a elevação do nível do mar, a seca

\footnotetext{
${ }^{9} \mathrm{O} \S 2 \circ$ do artigo 1ㅇda referida Convenção enuncia a definição de refugiado como qualquer pessoa que: "[...] em consequência dos acontecimentos ocorridos antes de $1^{\circ}$ de janeiro de 1951 e temendo ser perseguida por motivos de raça, religião, nacionalidade, grupo social ou opiniões políticas, se encontra fora do país de sua nacionalidade e que não pode ou, em virtude desse temor, não quer valer-se da proteção desse país, ou que, se não tem nacionalidade e se encontra fora do país no qual tinha sua residência habitual em consequência de tais acontecimentos, não pode ou, devido ao referido temor, não quer voltar a ele" (ONU, 1951).

10 Traduzido a partir de: "[...] become one of the foremost human crises of our times. This far they have been viewed as a peripheral concern, a kind of aberration from the normal order of things. In the world of the future, they are likely to become a prominent feature of our One Earth landscape. The phenomenon is an outward manifestation of profound change - a manifestation often marked by extreme deprivation, fear and despair".

${ }^{11}$ Além das mudanças do clima, existem outras causas ambientais que implicam no deslocamento forçado de pessoas: catástrofes ambientais de cunho natural, escassez de recursos naturais, processos de degradação ambiental, acidentes decorrentes de atividades vinculadas à produção energética, industrial e bélica; assim como projetos de desenvolvimento (FERNANDES, 2014, p. 32).
} 
e a desertificação, bem como da maior incidência de eventos ambientais extremos, subirá de 200 a 250 milhões para, possivelmente, 1 bilhão de pessoas até a metade do século XXI (LEAL-ARCAS, 2013, p. 28). Do mesmo modo, a Organização Internacional de Migração (OIM, 2009) estima que, até 2100, entre 100 e 200 milhões de seres humanos deixarão seus lares para buscar abrigo em outras localidades em razão das mudanças climáticas decorrentes do aquecimento global. Não menos importante, prevê-se que "um total de 4,5 bilhões de hectares ao redor do mundo - completos 35\% da superfície de terras secas do planeta - encontram-se em vários estágios de desertificação. Essas áreas são o lar de 850 milhões de pessoas"12.

O último relatório do Centro de Monitoramento de Deslocamento Interno (IDMC, 2018) ${ }^{13}$, publicado em maio de 2018, afirma que o número de desastres naturais relacionados às mudanças climáticas mais do que dobrou no decorrer das últimas duas décadas. Ademais, constatou que, entre 2008 e 2017, uma média anual de 26.4 milhões de pessoas foram obrigadas a se deslocar dentro de suas fronteiras nacionais em decorrência de tais fenômenos. Somente em 2017, 18.8 milhões de novos indivíduos tornaram-se deslocados internos em 135 países em razão de desastres ambientais relacionados às mudanças climáticas ${ }^{14} 15$.

Inobstante a Convenção das Nações Unidas Relativa ao Estatuto dos Refugiados de 1951 ter elencado circunstâncias que motivam a concessão do refúgio, quais sejam, a raça, a religião, a nacionalidade, o pertencimento a um grupo social e a opinião política, ela não exauriu todas as situações que poderiam integrar a definição de refugiado. Por outro lado, é sabido que o avanço técnico-científico ocasionou, a partir de então, não apenas a incidência de combates com armamentos cada vez mais perigosos e fatais para a humanidade, mas também a deterioração de

\footnotetext{
12 Frisa-se que as previsões apresentadas não possuem embasamento metodológico científico robusto o suficiente para fundamentar os debates políticos que permeiam o assunto. Por isso, são alvos de diversas críticas. Dentre elas, questiona-se as definições a serem utilizadas, bem como o período e a distância do deslocamento que devem ser levados em consideração para o computo do número total de pessoas deslocadas por conta dos efeitos adversos das mudanças climáticas. Em verdade, tais previsões geralmente são baseadas apenas no número de indivíduos que habitam regiões de risco, sem levar em consideração a multiplicidade de fatores que propiciam processos migratórios (IONESCO, MOKHNACHEVA, GEMENE. 2017, p. 14).

${ }^{13}$ Intitulado 2018 Global Report on Internal Displacement.

${ }^{14}$ Desse total, 8.6 milhões de deslocamentos decorrem de inundações e 7.5 milhões estão relacionados à tempestades tropicais. Dentre os países mais afetados em 2017 estão a China, as Filipinas, os Estados Unidos da América (EUA) e Cuba (IDMC, 2018, p. v).

${ }^{15} \mathrm{O}$ IDMC publica relatórios anuais com estimativas globais da localização e do número de deslocamentos internos no contexto de desastres associados à processos naturais (abalos sísmicos, atividade vulcânica e tsunamis), assim como decorrentes das mudanças climáticas (eventos climáticos extremos). Processos naturais de início lento, tais como desertificação e elevação do nível do mar, não são contabilizados pelo centro, uma vez que o cômputo requer metodologias próprias que ainda estão sendo discutidas (IONESCO, MOKHNACHEVA, GEMENE. 2017, p. 14).
} 
questões socioeconômicas, como o avanço da pobreza, a expansão do desemprego e, sobretudo, a intensificação da destruição da natureza, o que tem provocado a migração de milhares de pessoas em busca de novas perspectivas de vida (RAIOL, 2010, p. 96).

O conceito de refúgio vigente é produto de um demorado processo histórico que, apesar de ter possibilitado a proteção jurídica de pessoas perseguidas, não oportunizou brechas que permitissem a inclusão daqueles que necessitariam de abrigo diante dos novos rumos políticos, econômicos, sociais, bem como ambientais, despontados no decorrer das últimas décadas (RAIOL, 2010, p. 96).

A inviabilidade de enquadramento daqueles obrigados a se deslocar em razão de desastres ocasionados pelas mudanças climáticas na concepção tradicional de refugiados decorre da dificuldade em qualificar a devastação do meio ambiente como persecução, bem como em encaixála em um dos fundamentos que configuram o instituto do refúgio (LEHMAN, 2009). Em síntese, o termo perseguição restringe-se aos fundamentos elencados na lei, os quais, por sua vez, também devem girar em torno do bem fundado temor. Em vista disso, "as mudanças climáticas, as degradações e os desastres naturais [...] são novas razões que também podem conduzir milhares de pessoas a abandonarem o lugar em que residem ou até mesmo o país em que moram" (RAIOL, 2010, p. 140).

Foi na tentativa de alargamento dessa definição que os primeiros delineamentos para a conceitualização desta categoria de pessoas emergiram a partir da década de 1980. As expressões 
refugiado ambienta $\left.\right|^{16}$, migrante ambienta $1^{17}$ e deslocado ambiental ${ }^{18}$ designam pessoas ou grupos humanos que, diante da iminência de adversidades ambientais no local de seu habitat tradicional, sejam eles provocados por eventos de ordem natural ou induzidos pela ação humana, compõem a onda migratória tanto no âmbito interno de cada Estado quanto na esfera internacional, em caráter temporário ou permanente, com vistas ao resguardo das garantias fundamentais da pessoa humana (RAMOS, 2015, p. 739) $)^{19}$.

Processos migratórios não decorrem apenas de atividades geofísicas ${ }^{20}$, mas também de infortúnios impulsionados pelo desenvolvimento de práticas humanas. Além das mudanças do clima, outras causas ambientais levam à migração forçada de pessoas. São elas: catástrofes decorrentes de atividades geofísicas, escassez de recursos naturais e processos de degradação ambiental - que, consequentemente, podem motivar conflitos armados -, acidentes decorrentes de atividades vinculadas à produção energética, assim como grandes projetos de desenvolvimento (PIGUET, 2008,

\footnotetext{
${ }^{16}$ Essam El-Hinnawi dispôs, em 1985, que refugiados ambientais seriam "[...] pessoas obrigadas a abandonar, temporária ou definitivamente, a zona onde tradicionalmente viviam, em razão do visível declínio do ambiente (de ordem natural ou provocadas por pessoas), perturbando a sua existência e/ou a qualidade da mesma de tal maneira que a subsistência dessas pessoas entra em perigo". Três anos mais tarde, Jodi Jacobson trouxe a seguinte designação para a locução refugiados ambientais: "[...] aquelas pessoas temporariamente deslocadas devido a perturbações ambientais locais, como avalanches ou terremotos; aqueles que migram por causa da degradação ambiental, a qual tem prejudicado a subsistência ou, ainda, apresenta riscos inaceitáveis para a saúde humana; e aqueles reassentados porque a degradação da terra resultou em desertificação ou outras mudanças permanentes no habitat de origem". Não menos importante, em 1995, Norman Myers, propôs o seguinte conceito: "Refugiados ambientais são pessoas que já não conseguem ter uma vida segura em sua terra natal por causa de fatores ambientais de âmbito incomum. Esses fatores incluem a seca, a desertificação, desmatamentos, erosão do solo, escassez de água, mudanças climáticas, bem como desastres naturais, como ciclones, tempestades e inundações. Diante desses problemas ambientais, a população envolvida sente que não restam alternativas senão buscar o sustento em outros locais, dentro ou fora dos limites territoriais de seu país, de caráter temporário ou permanente" (SERRAGLIO, 2014, p. 78-80).

${ }^{17}$ A OIM, em 2007, definiu migrantes ambientais como "[...] pessoas ou grupo de pessoas que, em razão de mudanças imperiosas ou súbitas no ambiente, as quais afetam negativamente suas vidas ou condições de vida, obrigam-se a deixar suas residências habituais, ou optam por fazê-lo, temporária ou permanentemente, e que se movem tanto no seu país ou no estrangeiro" (OIM, 2009, p. 19).

${ }^{18}$ De acordo com o Appel de Limoges, elaborado e publicado em 2005 pelo francês Michel Prieur, os chamados deslocados ambientais seriam "[...] indivíduos, famílias e comunidades que enfrentam uma ruptura aguda ou gradual de seu ambiente natural, afetando, inevitavelmente, as condições básicas de sobrevivência e forçandoos, em face da situação de emergência, a deixar seus locais habituais de residência, conduzindo-os à reinstalação ou reassentamento em local diverso" (CRIDEAU, 2009, p. 468).

${ }^{19} \mathrm{O}$ termo refugiado ambiental caracteriza-se como a expressão mais utilizada para abordar o tema em razão das questões políticas que envolvem o termo refúgio. Tendo em vista que a análise pormenorizada dos diversos vocábulos e terminologias empregados para lidar com essa temática não é o objetivo central desta pesquisa, utilizar-se-á a redação migrantes ambientais para designar essa modalidade de pessoas.

${ }^{20}$ A expressão é utilizada para descrever desastres induzidos por alterações das características físicas do planeta Terra, tais como terremotos, deslizamentos, tsunamis e erupções vulcânicas. Logo, atividades geofísicas não se encontram diretamente relacionadas às mudanças climáticas (IONESCO, MOKHNACHEVA, GEMENE. 2017, p. 38).
} 
p. 1-13).

Reitera-se que as mudanças climáticas intensificam a vulnerabilidade de pessoas compelidas a abandonar seus locais de origem, nem sempre agindo como a única causa per se. Trata-se, pois, de um gatilho relacionado a uma complexa combinação de fatores econômicos, sociais, políticos e/ou culturais (RAMOS, 2015, p. 740). As motivações que ensejam a mobilidade humana são, via de regra, interdependentes e mutuamente agravantes. Em que pese a cumulatividade dos fatores ora mencionados ser prescindível, a simultaneidade e a combinação desses aspectos às mudanças climáticas acabam por acentuar crises humanitárias já existentes (FERNANDES, 2014, p. 22).

Ademais, os chamados migrantes ambientais podem se deslocar de forma voluntária ou forçada. A princípio, enquanto a migração voluntária resultaria do livre arbítrio do indivíduo, a forçosa obrigaria a saída do local de moradia, ou mesmo do país de origem (RAMOS, 2011, p. 76). Na prática, torna-se difícil distingui-las, o que impede a formulação e a implementação de políticas apropriadas. Comumente, a possibilidade de escolha varia de acordo com o grau de vulnerabilidade dos indivíduos e depende de três fatores principais, quais sejam: a necessidade, o desejo e a capacidade de migrar (IONESCO, MOKHNACHEVA, GEMENE. 2017, p. 28).

Enquanto alguns não precisam deixar seus locais de residência habitual por possuírem recursos suficientes para se adaptar in situ, outros - apesar da necessidade - desejam e optam por permanecer neles não apenas por razões culturais e/ou sociais, mas também devido à imperceptibilidade dos riscos ambientais. Contudo, quando tais indivíduos sentem a necessidade e desejam migrar, mas são incapazes de fazê-lo, geralmente em decorrência do alto grau de vulnerabilidade, tornam-se encurralados ${ }^{21}$. Nesse caso, o estresse ambiental funciona tão somente como um fator agravante de outras questões socioeconômicas pré-existentes (IONESCO, MOKHNACHEVA, GEMENE. 2017, p. 28).

Por fim, deve-se mencionar que não se impõe que essas pessoas cruzem as fronteiras de seus países de origem, de forma temporária ou permanente, para que se enquadrem na condição de migrantes. Basta, unicamente, que o sujeito seja compelido a abandonar seu local de residência habitual: não se distingue, portanto, se o indivíduo ou grupo humano atravessou ou não uma fronteira internacional (RENAUD et al., 2007, p. 13).

Verdade seja, grande parte dos migrantes ambientais não deixa seu país de origem, uma vez que visam retornar ao local afetado o mais breve possível (TIBERGHIEN, 2008, p. 18). Há um forte consenso, dessa forma, de que os deslocados por desastres naturais permanecem dentro de suas

\footnotetext{
${ }^{21}$ Do inglês, trapped.
} 
próprias fronteiras ${ }^{22}$. Ao contrário dos refugiados, o número de indivíduos que atravessam os limites territoriais do local de residência habitual em razão de catástrofes ambientais é muito menor do que a quantidade de deslocados internos ${ }^{23}$ :

Os dados estatísticos oficiais confirmam essa tendência. O Alto Comissariado das Nações Unidas para Refugiados (ACNUR), no relatório Tendências Globais 2008, contabilizou 42 milhões de pessoas forçadamente deslocadas, das quais 15,2 milhões são refugiados, 827 mil solicitantes de asilo e 26 milhões de deslocados internos (RAMOS, 2011, p. 72).

Tendo em vista que esses deslocamentos geralmente ocorrem de áreas rurais para centros urbanos, debates sobre os impactos dos fluxos migratórios e a dinâmica dos migrantes nas relações sociais, econômicas, políticas e culturais das cidades passaram a ganhar destaque (VIVEKANADA, 2018). Apesar da urbanização ter a (i)migração como uma de suas características centrais, verificarse-á, na sequência, que quando tal processo acontece de forma rápida, descontrolada e desordenada, a chegada de novos habitantes aos grandes centros urbanos é vista como sendo responsável pela falta de moradia e infraestrutura, pela precariedade na prestação de serviços, assim como pela intensificação da instabilidade social.

\section{A REPERCUSSÃO DAS MUDANÇAS CLIMÁTICAS SOBRE OS CENTROS URBANOS E A RECEPÇÃO/ACOLHIMENTO DOS MIGRANTES AMBIENTAIS}

Processos migratórios se correlacionam à expansão de zonas urbanas. Isso porque grande parte das populações deslocadas devido aos efeitos das mudanças climáticas direciona-se para as cidades, as quais passaram a atuar não apenas como local de origem, mas também como local de trânsito e destino final para aqueles que buscam melhores condições de vida (HABITAT III, 2015, p. 02).

Atualmente, mais da metade da população mundial -3.6 bilhões de pessoas -, vive em áreas

\footnotetext{
${ }^{22}$ Enquanto países industrializados preocupam-se com a intensificação dos fluxos migratórios dentro dos seus limites territoriais, frisa-se que o deslocamento transfronteiriço de pessoas raramente é uma opção. Quando ocorre, acontece em âmbito regional e entre países em desenvolvimento (IONESCO, MOKHNACHEVA, GEMENE. 2017, p. 20).

${ }^{23}$ De acordo com os Princípios Orientadores relativos aos Deslocados Internos (1998), deslocados internos são "pessoas, ou grupos de pessoas, forçadas ou obrigadas a fugir ou abandonar as suas casas ou seus locais de residência habituais, particularmente em consequência de, ou com vista a evitar, os efeitos dos conflitos armados, situações de violência generalizada, violações dos direitos humanos ou calamidades humanas ou naturais, e que não tenham atravessado uma fronteira internacionalmente reconhecida de um Estado" (UNHCR, 1998).
} 
urbanas $^{24}$. Até 2050, o aumento populacional, associado a uma elevada taxa de urbanização ${ }^{25} 26$, fará com que o número de habitantes em centros urbanos suba de 5.6 para 7.1 bilhões, compreendendo $69 \%$ de toda a população global ${ }^{27}$. Em razão disso, não é de se surpreender que as regiões urbanas sejam responsáveis por cerca de $70 \%$ das atividades econômicas desenvolvidas, por $70 \%$ de todo resíduos sólidos produzidos, pelo consumo de $60 \%$ de toda energia disponível e por $40 \%$ das emissões de GEE (AVIS, 2016, p. 04).

Ao atrair indivíduos - como os migrantes ambientais -, em busca de oportunidades de emprego, qualificação profissional e acesso a bens e serviços, áreas urbanas acabam por intensificar a emissão de GEE na atmosfera. A crescente demanda por sistemas de infraestrutura e transporte exige um elevado consumo de energia e, além disso, traz implicações para a qualidade do ar, a disponibilidade de água, o uso da terra, bem como a gestão de resíduos (MEYER, 2013, p. 03).

Ao mesmo tempo, cidades tornam-se suscetíveis e incapazes de lidar com os efeitos adversos das mudanças climáticas, expondo milhões de habitantes, na sua maioria moradores de assentamentos informais ou pertencentes a grupos vulneráveis, a diversos desastres ambientais. Prevê-se que o aumento do número de ondas e ilhas de calor, maior frequência e intensidade de secas, chuvas com consequentes inundações, e elevação do nível do mar em zonas costeiras comprometerão não apenas o fornecimento de água e tratamento de esgoto, mas também os sistemas locais de energia, transporte e saúde pública (ROSENWEIG, 2011, p. 11).

Não se pode perder de vista que aglomerados humanos sempre tiveram que lidar com problemas decorrentes da instabilidade de suas encostas, do alagamento de amplas áreas, e da destruição da infraestrutura urbana por desastres ambientais. "Seria um equívoco atribuir tais problemas exclusivamente às mudanças climáticas. Porém, é certo que eventos climáticos extremos tendem a se agravar, além de se tornarem mais frequentes" (XXV PRÊMIO JOVE CIENTISTA, 2018, p.

\footnotetext{
${ }^{24}$ Áreas urbanas são espaços ocupados por cidades e municípios que apresentam alta densidade demográfica se comparados com seus arredores. Essas se caracterizam pela edificação contínua e pela existência de infraestrutura que compreende ao conjunto de serviços públicos que permitem a vida da população (AVIS, 2016, p. 03).

25 Trata-se de indicador que mede o crescimento percentual da população que vive em áreas urbanas em relação à população total considerado em períodos determinados (AVIS, 2016, p. 03).

${ }^{26}$ Nesse contexto, existiam 512 cidades com pelo menos 01 milhão de habitantes em 2016 . Estima-se que esse número subirá para 662 até 2030. Ademais, prevê-se o surgimento de 10 novas megacidades nesse período, totalizando 41 aglomerações urbanas com mais de 10 milhões de habitantes (UN HABITAT, 2017, p. 03).

${ }^{27}$ A população global urbana ultrapassou a rural no ano de 2007: enquanto que, em 1950, apenas $30 \%$ da população era urbana, em 2014 esse percentual atingiu 54\%. O IPCC aponta que o número de indivíduos residindo em centros urbanos alcançará dois terços de toda a população mundial até 2050. Tal expansão acontecerá, sobretudo, em países em desenvolvimento que não possuem infraestrutura necessária para suportar esse crescimento sem impactos sociais e ambientais (PBMC, 2016, p. 19).
} 
107).

De acordo com o IPCC (2014, p. 18), as variações climáticas prejudicarão o amplo espectro de funções, infraestruturas, serviços e edificações urbanos. A vulnerabilidade desses sistemas à tal fenômeno varia de acordo com o grau de desenvolvimento, resiliência e adaptabilidade. Deste modo, as alterações do clima tendem a acentuar pressões já existentes, sobretudo em países em desenvolvimento, "onde grande parte da população é desprovida de serviços básicos de saneamento, o tráfego de vias urbanas é caótico e a segurança energética está constantemente em discussão" (PBMC, 2016, p. 39).

Ao passo que eventos extremos relacionados a secas influenciam a quantidade e a qualidade dos recursos hídricos para o abastecimento das cidades, alterações no regime de chuvas espalham e carregam resíduos sólidos expostos no ambiente urbano, obstruindo galerias e, consequentemente, provocando alagamentos (PBMC, 2016, p. 57).

As mudanças climáticas afetam a oferta de energia não apenas no que diz respeito à base de recursos energéticos, uma vez que fontes renováveis tornam-se sensíveis às alterações do clima, mas também quanto a transmissão e distribuição de eletricidade, dado que linhas aéreas encontramse expostas à ocorrência de eventos climáticos extremos. Da mesma forma, os sistemas de transporte - rodoviário, ferroviário, aéreo e aquaviário - tornam-se vulneráveis às condições meteorológicas de tempo e clima, prejudicando a mobilidade humana e a qualidade de vida das populações, assim como impedindo o crescimento econômico (PBMC, 2016, p. 44-45).

Outrossim, as perturbações à saúde pública ocorrem de forma direta e indireta. Enquanto essa se refere às alterações dos recursos fundamentais à saúde humana - água, ar e alimentos -e do ciclo de vida de insetos que favorecem a dispersão de agentes infecciosos; aquela diz respeito às ondas de calor e temperaturas extremas que afetam a fisiologia do corpo humano e outros eventos climáticos extremos que geram traumas físicos, causando, em algumas situações, até mesmo óbitos (XXV PRÊMIO JOVE CIENTISTA, 2018, p. 107).

Já não bastassem os desafios enfrentados pelos grandes centros urbanos em razão das mudanças climáticas, os migrantes ambientais se confrontam ainda com outros obstáculos oriundos do acelerado processo de urbanização. A situação de vulnerabilidade ${ }^{28}$, acrescida da constante deterioração do meio ambiente, enseja crises socioambientais sem precedentes, acomete o bem-

\footnotetext{
${ }^{28}$ Os migrantes ambientais são susceptíveis à violência urbana e criminalidade, ao tráfico de pessoas (sobretudo de crianças e mulheres), à exploração de mão-de-obra e agências de recrutamento nãoregulamentadas, ao fornecimento de documentos falsos, à prestação ilegal de serviços, dentre outros (AVIS, 2016, p. 28).
} 
estar social e econômico, bem como provoca a violação de direitos humanos dos recém-chegados (MURILLO, 2017, p. 03). Em verdade, atribui-se a falta de moradia e infraestrutura, a precariedade na prestação de serviços e a intensificação da instabilidade social aos processos migratórios. Nesse sentido, tem-se que:

[...] o rápido processo de urbanização, com a sua crescente demanda por moradia, acesso à recursos e prestação de outros serviços públicos, pressiona ainda mais a já debilitada infraestrutura física e social de grandes centros urbanos [...]. Ondas migratórias adicionais tendem a exacerbar vulnerabilidades pré-existentes relacionadas à desigualdade social, pobreza e informalidade (trabalho informal e assentamentos), agravando a situação daqueles expostos à fatores de riscos ambientais. Acentua-se, deste modo, a capacidade adaptativa das cidades às mudanças climáticas (WARN, ADAMO. 2014, p. 01) 29 .

Diante da incapacidade das cidades em absorver o número cada vez maior de trabalhadores, os empregos informais tornam-se alternativas e possibilitam a subsistência de famílias e populações inteiras em assentamentos urbanos informais (AVIS, 2016, p. 28).

Os empregos informais são atividades sem vínculos e/ou sem a devida regularização pelos órgãos governamentais competentes, sendo desprovidos de benefícios como remuneração fixa, férias pagas e previdência social. Aqueles que integram a economia informal enfrentam uma série de dificuldades. São trabalhadores subvalorizados que possuem longas jornadas de trabalho em locais, por vezes, insalubres, mediante o recebimento de baixos salários (AVIS, 2016, p. 28).

Por sua vez, os assentamentos urbanos informais, também conhecidos como favelas, caracterizam-se por áreas residenciais densamente povoadas em que a garantia de uso e posse da terra ou, ainda, das respectivas habitações, é inexistente. Geralmente, são regiões que apresentam moradias edificadas em desacordo com o plano diretor municipal e localizadas em áreas de risco, o que limita o acesso a bens e serviços, assim como à infraestrutura básica ${ }^{30}$. A expansão dessas localidades é um fenômeno que acompanha o crescimento urbano: estima-se que $25 \%$ da população

\footnotetext{
${ }^{29}$ Traduzido a partir de: "[...] rapid urbanization, accelerating demand for housing, resource supplies and social and health services, place pressure on already stretched physical, social and regulatory infrastructure [...]. Additional migration to cities is likely to exacerbate pre-existing vulnerabilities related to inequality, poverty, indigence and informality (informal work and settlements), and worsen the situation of those exposed to environmental risk factors. This places further stress on the ability of cities to adapt to climate change".

${ }^{30} \mathrm{~A}$ falta de prestação de serviços básicos, como saneamento, abastecimento de água potável, eletricidade, policiamento, infraestrutura em geral e regularização fundiária, encontra-se intimamente relacionada ao nível de bem-estar dos moradores dos assentamentos urbanos informais, que acabam tendo chances reduzidas de escapar da pobreza. Nesse contexto, a prestação de serviços básicos é limitado não apenas pela falta de coordenação e governança, mas também pelo rápido processo de urbanização (AVIS, 2016, p. 30-32).
} 
urbana mundial resida em assentamentos informais, com 213 milhões de novos assentados desde 1990 (UN-HABITAT, 2013, p. 126).

Em síntese, como a maior parte dos migrantes ambientais se desloca internamente para centros urbanos de países em desenvolvimento, caracterizados pela má-governança e pela precariedade no fornecimento de serviços básicos a seus habitantes, muitos acabam tendo seus direitos civis, políticos e sociais enfraquecidos ${ }^{31}$, aumentando as tensões sociais e os índices de violência (CHAWLA, 2017, p. 02).

A reformulação de programas e serviços que visam a melhoria da qualidade de vida da população de áreas urbanas diante dos efeitos das mudanças climáticas e da crescente chegada de migrantes ambientais torna-se necessária.

Há que se falar, portanto, em planejamento urbano. Responsável pelo desenvolvimento de processos de tomada de decisões relacionadas à metas econômicas, sociais, culturais e ambientais por meio de estratégias e planos amparados em princípios políticos e outros mecanismos institucionais e de participação, trata-se "de instrumento poderoso para revisar formatos e funções de cidades e regiões, visando gerar crescimento econômico endógeno, prosperidade e emprego, lidando com as necessidades dos grupos mais vulneráveis" (UN-HABITAT, 2015, p. 28) ${ }^{32}$.

O uso do planejamento urbano possibilita o melhor gerenciamento das mudanças demográficas urbanas - tais como crescimento, estagnação e/ou declínio populacional - e favorece a qualidade de vida de moradores de assentamentos urbanos. Além de lideranças políticas e parcerias que envolvam todas as partes interessadas, um sistema de regulamentações que ofereça uma estrutura jurídica sólida, um planejamento e desenho urbano sólido e flexível, bem como investimentos públicos devem estar equilibrados para garantir resultados positivos e realizáveis ${ }^{33}$. Em outras palavras,

\footnotetext{
${ }^{31}$ Quando o processo de migração ambiental ultrapassa fronteiras nacionais, obstáculos adicionais são enfrentados, como barreiras linguísticas e culturais. Essas acabam gerando xenofobia, que se caracteriza pelo medo, aversão ou a profunda antipatia em relação aos estrangeiros. O medo do desconhecido pode ser mascarado no indivíduo como aversão ou ódio, gerando preconceitos (WARN, ADAMO. 2014, p. 01).

${ }^{32}$ Traduzido a partir de: "[...] it is a powerful instrument for reshaping the forms and functions of cities and regions in order to generate endogenous economic growth, prosperity and employment, while addressing the needs of the most vulnerable".

${ }^{33}$ Frisa-se que o planejamento urbano de uma cidade pode adotar diversas estratégias de desenvolvimento. Planos de desenvolvimento, por exemplo, priorizam decisões de investimento e incentivam sinergias e interações entre áreas urbanas separadas. Planos de uso do solo podem contribuir para a proteção de áreas ambientalmente vulneráveis e para a regulação do mercado relacionado ao solo urbano. Ainda, enquanto planos de revitalização contribuem para a minimização dos custos de transporte e entrega de serviços, planos de modernização aumentam as densidades residencial e econômica e integram as comunidades locais (UNHABITAT, 2015, p. 03).
} 
[...] planejamento urbano tem o potencial de desempenhar um papel transformador na melhoria da qualidade de vida das comunidades urbanas e no combate à pobreza. [...] Em diversos países em desenvolvimento, a sua implementação é desafiadora não apenas devido à processos desatualizados, mas também em razão do conhecimento público limitado. Como resultado, cidades comumente se desenvolvem de forma não-inclusiva. Ademais, a globalização e a desregulamentação do mercado acabam por transferir a tomada de decisões para o setor privado (AVIS, 2016, p. 11) ${ }^{34}$.

Ademais, o estabelecimento de governança urbana $^{35}$ viabiliza o desenvolvimento e funcionamento sustentável das cidades, assim como o resguardo das garantias fundamentais a todos que nelas residem. Isso porque, a maneira com que instituições públicas e privadas planejam e administram os grandes centros urbanos mostra-se crucial para o bem-estar de seus habitantes: "pela boa governança urbana, os cidadãos são providos com a plataforma que permite a utilização máxima de seus talentos, com vistas a melhorar suas condições socioeconômicas" (MARÇAL, 2018).

Isso posto, o planejamento e a governança urbana contribuem para o desenvolvimento sustentável não apenas no que diz respeito ao crescimento econômico sustentado e à proteção ambiental, mas também quanto à promoção de um desenvolvimento social inclusivo(AVIS, 2016, p. 05). É nesse contexto que os Objetivos de Desenvolvimento Sustentável (ODS) ganham relevância, como se analisará na sequência.

\section{O ALINHAMENTO DOS OBJETIVOS DE DESENVOLVIMENTO SUSTENTÁVEL (ODS) RELACIONADOS AOS CENTROS URBANOS COM A MIGRAÇÃO AMBIENTAL}

Aprovado durante a Cúpula das Nações Unidas para o Desenvolvimento Sustentável, em setembro de 2015, o documento Transformando Nosso Mundo: A Agenda 2030 para o Desenvolvimento Sustentável (Agenda 2030) é resultado de um processo iniciado em 2012, durante

\footnotetext{
${ }^{34}$ Traduzido a partir de: "[...] Planning has the potential to play a transformational role in improving the quality of life of urban communities and tackling poverty. [...] In many developing countries, effective formal planning is challenging because of out-of-date planning processes; and limited public knowledge of or compliance with land-use regulation. As a result, cities often develop in non-inclusive ways. Further, globalization, deregulation and free market policies often shift decision-making powers to the private sector".

35 De acordo com o Programa das Nações Unidas para os Assentamentos Humanos (ONU-HABITAT), governança urbana designa-se como "programas que permitem o funcionamento do equipamento urbano, o ambiente propício que requer quadros legais adequados, processos políticos, administrativos e gerenciais eficientes, assim como instituições locais fortes e capazes de responder às necessidades dos cidadãos".
} 
a Conferência das Nações Unidas sobre Desenvolvimento Sustentáve ${ }^{36}$, com o intuito de revisar e atualizar os Objetivos de Desenvolvimento do Milênio (ODM) (UN-HABITAT, 2016, p. 03) 37 .

A Agenda 2030 vincula-se à proteção das pessoas, à preservação do planeta, à promoção da paz, da prosperidade e de parcerias por meio da orientação das políticas nacionais e das atividades de cooperação internacional até 2030. Além de englobar 17 Objetivos de Desenvolvimento Sustentável $(\mathrm{ODS})^{38}$, ela lista 169 metas, todas orientadas a traçar uma visão universal e integrada capaz de equilibrar as três dimensões do desenvolvimento sustentável: a econômica, a social e a ambiental (MINISTÉRIO DO PLANEJAMENTO, DESENVOLVIMENTO E GESTÃO, 2017, p. 09).

Dentre os ODS, é o Objetivo 11 - Tornar as cidades e os assentamentos humanos inclusivos, seguros, resilientes e sustentáveis que merece destaque nesta pesquisa. As metas relacionadas ao ODS 11 almejam o acesso de todos à habitação segura, adequada e a preço acessível; o acesso a sistemas de transportes seguros e a melhoria da segurança rodoviária; a urbanização inclusiva e sustentável; a salvaguarda do patrimônio cultural e natural global; a redução do número de mortes e pessoas afetadas por catástrofes; a redução do impacto ambiental negativo per capita das cidades; bem como o acesso universal a espaços públicos seguros, inclusivos, acessíveis e verdes (ONU-BR, 2018).

Vale mencionar que o ODS trabalha com o conceito de cidades resilientes ${ }^{39}$. Centros urbanos resilientes são aqueles que se encontram preparados para adversidades atuais e futuras, de forma a limitar sua magnitude e gravidade. Isto é, tão logo ocorra um infortúnio ambiental, tais localidades são capazes de responder com rapidez, de modo equitativo e eficiente (THE WORLD BANK GROUP, 2016, p. 06). Dito de outra forma, trata-se da "capacidade de indivíduos, comunidades, empresas,

\footnotetext{
${ }^{36}$ Também conhecida como Rio+20, trata-se de conferência realizada em 2012 com o objetivo de renovar o compromisso político com os preceitos que permeiam o desenvolvimento sustentável.

${ }^{37}$ Os ODM resultam da Declaração do Milênio, adotada por 191 Estados-membros da Organização das Nações Unidas (ONU) no ano 2000. O documento apresenta 08 objetivos e 22 metas que, uma vez implementados nas agendas internacionais, nacionais e locais, foram responsáveis por grandes avanços na promoção do desenvolvimento humano entre 2000 e 2015 (MINISTÉRIO DO PLANEJAMENTO, DESENVOLVIMENTO E GESTÃO, 2017, p. 09).

${ }^{38}$ Os ODS envolvem temáticas diversificadas: erradicação da pobreza, segurança alimentar e agricultura, saúde, educação, igualdade de gênero, redução das desigualdades, energia, água e saneamento, padrões sustentáveis de produção e consumo, proteção e uso sustentável dos oceanos e dos ecossistemas terrestres, crescimento econômico inclusivo, infraestrutura e industrialização, governança e meios de implementação, assim como mudanças do clima e cidades sustentáveis (MINISTÉRIO DO PLANEJAMENTO, DESENVOLVIMENTO E GESTÃO, 2017, p. 09).

${ }^{39} \mathrm{O}$ termo resiliência compreende a capacidade dos ecossistemas em persistir no seu estado original, sendo esses sujeitos a perturbações. Em outras palavras, significa a capacidade de um sistema, comunidade ou sociedade, exposta a riscos, de resistir, absorver, acomodar e se recuperar a partir dos efeitos de um perigo, num prazo adequado e de forma eficiente, com a preservação e restauração de suas estruturas básicas essenciais e funções (PBMC, 2016, p. 22).
} 
instituições e cidades se adaptarem às condições de mudança e manterem ou recuperarem a funcionalidade e a vitalidade frente a estreses, choques e pressões crônicas, e emergirem mais fortes" (PBMC, 2016, p. 21).

Para tanto, a organização de serviços e infraestrutura que suporte a população, o compartilhamento de informações sobre quem está exposto e se encontra em situação de vulnerabilidade, a urbanização sustentável por um governo local competente, inclusivo e transparente, bem como o empoderamento dos cidadãos para participação, decisão e planejamento de sua cidade com as autoridades locais fazem-se necessários (ONU-BR, 2018).

Logo, processos de urbanização podem trazer importantes benefícios para o desenvolvimento econômico, cultural e social dos centros urbanos. Quanto maior a densidade demográfica de uma cidade, mais fácil se torna o fornecimento de serviços básicos a um custo per capita relativamente baixo. É dizer, a grande concentração de indivíduos em uma faixa de área determinada agiliza e otimiza a prestação de serviços, tornando possível, assim, o atendimento de um número maior de pessoas e a redução de gastos público (UNFPA, 2013, p. 04). Por isso, cidades sustentáveis podem auxiliar a sociedade contemporânea a "superar alguns dos seus principais desafios, tais como pobreza, desigualdades sociais, degradação ambiental, mudanças climáticas e conflitos, todas elas elencadas na Agenda 2030" (UN-HABITAT, 2016, p. 06) ${ }^{40}$.

Ao endossar um objetivo que aborda especificamente as cidades, a comunidade internacional reconheceu o processo de urbanização e os centros urbanos como forças transformadoras do desenvolvimento sustentável. Ainda que o ODS 11 não faça referência ao papel desempenhado e às contribuições trazidas pelos migrantes ambientais a todo esse processo, o parágrafo 29 da Agenda 2030 assim dispõe ${ }^{41}$ :

Reconhecemos a contribuição positiva dos migrantes para o crescimento inclusive e o desenvolvimento sustentável. Reconhecemos também que a migração internacional é uma realidade multidimensional de grande relevância para o desenvolvimento dos países de origem, de trânsito e de destino, o que exige respostas coerentes e globais. Iremos cooperar internacionalmente para garantir uma migração segura, ordenada e regular que envolve o pleno respeito pelos direitos humanos e o tratamento humano dos migrantes, independentemente do status da migração, dos refugiados e das pessoas deslocadas. Essa cooperação deverá também reforçar a

\footnotetext{
${ }^{40}$ Traduzido a partir de: "[...] overcome some of its major global challenges, including poverty, inequality, environmental degradation, climate change and conflicts, which are critical elements of the 2030 Agenda".

${ }^{41}$ Nesse contexto, a Opinião Consultiva 23/2017 (OC 23/17), publicada pela Corte Interamericana de Direitos Humanos em 15 de novembro de 2017, ressalta que a Assembleia Geral das Nações Unidas, ao adotar a Agenda 2030, reconheceu a interdependência e interligação entre os ODS (ROBINSON, 2017).
} 
resiliência das comunidades que acolhem refugiados, particularmente nos países em desenvolvimento (ONU, 2018).

Ademais, o ODS 10 - Reduzir a desigualdade dentro dos países e entre eles destaca a necessidade de se facilitar a migração e a mobilidade de forma ordenada, segura, regular e responsável das pessoas, inclusive por meio da implementação de políticas planejadas e bem geridas (ONU-BR, 2018).

Logo, urbanização e migração são fenômenos que se relacionam. Isso porque processos de crescimento urbano sempre envolvem, em alguma medida, o acolhimento de novos habitantes (UNESCO, 2016, p. 11). Apesar da intensificação de processos migratórios em decorrência dos efeitos adversos das mudanças climáticas no decorrer das últimas décadas, centros urbanos continuam ignorando tal fenômeno no momento de formular políticas promotoras do desenvolvimento urbano sustentável. Deste modo, migrantes ambientais são comumente negligenciados pelos discursos relacionados a processos de urbanização ${ }^{42}$ ou, ainda, vistos como ameaças e sinônimo de instabilidade social.

Em verdade, o acolhimento desses indivíduos pode oferecer vantagens sociais, econômicas e culturais para os centros urbanos. É o que se analisa a seguir.

\section{O RECONHECIMENTO E A RELEVÂNCIA DA MIGRAÇÃO AMBIENTAL PARA OS CENTROS URBANOS}

Inobstante a migração ambiental em direção às áreas urbanas ser um dos desafios do século XXI, restou evidenciado que esse grupo de pessoas é negligenciado pelos discursos relacionados a processos de urbanização. Desprovidos de mecanismos adequados de proteção, esses habitantes acabam sendo excluídos e se tornam invisíveis aos olhos da sociedade: "o modelo tradicional de urbanização constatado no decorrer das últimas décadas tem fomentado a segregação ao invés da integração" (AMRITH, 2016, p. 02) $)^{43}$.

Em uma lógica alicerçada na ideia de inclusão e exclusão ${ }^{44}$, os migrantes ambientais representam a imagem do outro, ou seja, a possível representação de uma ameaça e sinônimo de

\footnotetext{
42 O planejamento urbano de cidades também deve refletir as metas do ODS 13 - Tomar medidas urgentes para combater a mudança climática e seus impactos. Frisa-se que os deslocamentos humanos causados em decorrência dos efeitos adversos das mudanças climáticas também não são abordados por este ODS.

${ }^{43}$ Traduzido a partir de: "[...] the generic urbanization model over the past decades has fostered segregation over integration".

${ }^{44}$ De acordo com Giddens, relaciona-se inclusão à igualdade e exclusão à desigualdade. Inclusão refere-se a cidadania, direitos e obrigações civis e políticas que todos os membros de uma sociedade deveriam ter, não apenas formalmente, mas como uma realidade de suas vidas. Ademais, coaduna-se com oportunidades e
} 
instabilidade social e/ou crise pelos locais de destino final ${ }^{45}$. Em razão disso, medidas para obstaculizar o acolhimento dessas pessoas são aplicadas ${ }^{46}$, gerando um espaço de tensão entre a garantia dos Direitos Humanos e a manutenção do controle migratório (NUNES, 2018, p. 279).

Como a maior parte dos migrantes ambientais se desloca internamente para centros urbanos de países em desenvolvimento, muitos acabam tendo seus direitos civis, políticos e sociais enfraquecidos ${ }^{47}$. Além de acentuar a falta de moradia, a deterioração da saúde pública, o acesso a bens e serviços e infraestrutura básica, acredita-se que tal fenômeno provoca tensões nas comunidades locais, aumentando, consequentemente, os índices de violência (AVIS, 2016, p. 02). Esses indivíduos tornam-se, portanto, responsáveis por problemas sociais que, na verdade, têm causas locais, destacando-se a escassez de serviço público adequado (FARENA, 2012, p. 135).

Quando o processo de migração ambiental ultrapassa fronteiras nacionais, obstáculos adicionais são enfrentados, como barreiras linguísticas e culturais. Essas acabam gerando xenofobia, que se caracteriza pelo medo, aversão ou antipatia em relação aos estrangeiros (CHAWLA, 2017, p. 02). De acordo com a Declaração e Programa de Ação adotados durante a III Conferência Mundial das Nações Unidas de Combate ao Racismo, Discriminação Racial, Xenofobia e Formas Conexas de Intolerância, realizada em Durban no ano de 2001, as populações migrantes são altamente vulneráveis à discriminação, aos abusos e à xenofobia:

envolvimento dos indivíduos no espaço público. Por sua vez, exclusão diz respeito àqueles que estão em baixo, excluídos do fluxo principal de oportunidades que a sociedade tem a oferecer. Trata-se do afastamento das instituições públicas por parte dos grupos mais afluentes, que optam por viver em separado do resto da sociedade. Frisa-se que a exclusão não está ligada a graduações de desigualdades, mas a mecanismos que atuam para destacar pessoas do fluxo social prevalecente (GIDDENS, 1999, p. 112).

${ }^{45}$ Segundo Castles, há que se falar em dois tipos de processos migratórios: os bons englobam trabalhadores qualificados e/ou necessários para vagas específicas de trabalho, geralmente localizados no hemisfério norte e com valores culturais ocidentais; e os indesejados abarcam trabalhadores de baixa ou sem qualificação profissional, imigrantes forçados, refugiados e pessoas cujo modo de vida apresenta valores não ocidentais ou particulares. Ao passo que os primeiros circulam livremente, aos segundos restam o fechamento das fronteiras nacionais e a criminalização (CASTLES, 1993, p. 23).

${ }^{46}$ As formas com que os centros urbanos enfrentam processos migratórios podem ser distinguidas em exclusão (migrantes devem retornar ao seu país de origem), assimilação (apesar de negar o reconhecimento das diferenças culturais, oferece aos migrantes acesso à cidadania com o pressuposto de que esses assimilarão os valores culturais e regras de convivência locais), provisoriedade (migrantes são considerados residentes temporários que retornarão ao seu local de residência habitual tão logo finalizem prestação de trabalho por tempo determinado), e multiculturalismo (reconhece-se a identidade cultural dos migrantes e, por isso, espera-se a implementação de medidas que protejam suas especificidades, ainda que do ponto de vista forma) (MELO, 2015, p. 158).

${ }^{47}$ Dentre eles, destaca-se o direito à moradia, o direito de educação, a garantia da saúde, direito ao trabalho, direitos políticos como votar e ser votado, participar de plebiscitos ou referendos; e, no caso de migrantes que cruzam fronteiras nacionais, soma-se à preservação da identidade cultural. 
Reconhecemos que a xenofobia contra estrangeiros, particularmente contra migrantes, refugiados e aqueles que solicitam asilo, constitui-se em uma das principais fontes de racismo contemporâneo, e que a violação dos direitos humanos contra membros de tais grupos ocorre em larga escala no contexto das práticas discriminatórias, xenófobas e racistas (UNESCO, 2011).

Nesse lanço, enfatiza-se que a xenofobia decorre do preconceito e tem, como consequência, a discriminação de grupos inteiros de indivíduos. Entende-se por preconceito posicionamentos aceitos sem verificação, mas sim pela inércia, respeito ou temor, resistindo a qualquer refutação baseada em argumentos racionais. Dito de outra forma, trata-se de "opinião errônea tomada fortemente por verdadeira" que é "acolhida acrítica e passivamente pela tradição, pelo costume ou por uma autoridade de quem aceitamos as ordens sem discussão" (BOBBIO, 2002, p. 103).

De acordo com Bobbio (BOBBIO, 2002, p. 105), preconceitos podem ser compartilhados por grupos sociais inteiros e direcionados à outros, geralmente minorias e/ou grupos vulneráveis. Quando coletivos, derivam da forma distorcida com que um grupo social julga o outro, provocando incompreensão, rivalidade e inimizades. Em razão disso, "a necessidade que tem o povo hospedante de conviver com indivíduos de quem mal se conhecem os costumes geram atitudes de desconfiança, que vão do deboche verbal à recusa de qualquer forma de comunicação ou contato, da segregação à agressão" (BOBBIO, 2002, p. 120).

É desse modo que a discriminação emerge. Comumente utilizada com conotação pejorativa e fundada em juízos de valores ${ }^{48}$ injustos, caracteriza-se por diferenciações ilegítimas que levam aqueles que deveriam ser tratados de modo igual a serem tratados de forma desigual (BOBBIO, 2002, p. 126). A exclusão do gozo de certos direitos, a marginalização social e a segregação são algumas das suas características. Essa última consiste em impedir a mistura dos diversos entre os iguais, quer dizer, "o diferente deve permanecer diferente" (BOBBIO, 2002, p. 107).

Verdade seja, as legislações restritivas de países desenvolvidos e em desenvolvimento mantêm grupos inteiros de deslocados na clandestinidade (FARENA, 2012, p. 131). Ao se permitir a categorização de pessoas como ilegais e/ou irregulares, criminaliza-se e desumaniza-se o migrante ambiental, o que acarreta a violação da dignidade da pessoa humana. É dizer, "por via de uma palavra, deixam-se milhares de seres humanos simplesmente fora da aplicabilidade, do escopo e da

\footnotetext{
${ }^{48}$ Enquanto juízo de fato diz respeito à diversidade entre homem e mulher, ou entre um grupo social e outro, por exemplo; juízo de valor relaciona-se ao fato de um ser superior ao outro, ou um grupo ser considerado civilizado e o outro bárbaro.
} 
proteção da lei, em ofensa aos princípios da universalidade, indivisibilidade e inalienabilidade ${ }^{49} \mathrm{da}$ proteção dos Direitos Humanos" (FARENA, 2012, p. 134).

Em síntese, algumas constantes que acentuam desigualdades nos processos migratórios podem ser caracterizadas como: "no plano jurídico, a discriminação; no plano existencial, a precariedade; no plano trabalhista, a provisoriedade e a incerteza; no plano social, a falta de infraestruturas; no plano político, a marginalização; no plano cultural, a involução e a segregação" (MELO, 2015, p. 150).

Isso posto, por muito tempo, ao invés de realçar os benefícios dos migrantes ambientais para a vida urbana, a sociedade contemporânea buscou maneiras de dificultar o seu acesso aos centros urbanos (AMRITH, 2016, p. 02). É importante que se perceba que a dinâmica dos movimentos populacionais não traz apenas desafios, mas também evidencia potenciais pontos de partida para oportunas expansões (UNFPA, 2013, p. 03).

Cumpre observar que cidades sempre foram moldadas por processos migratórios e refletem a dinâmica daqueles que por ela passam. Os recém-chegados - sejam eles de cidades situadas dentro ou fora das fronteiras nacionais ou, ainda, de áreas rurais - contribuem para o aumento da diversidade e para a expansão das complexas interações urbanas (UNESCO, 2016, p. 21). Nesse sentido, Herrera Flores (2009, p. 166) destaca que

[...] devemos reconhecer, primeiro, o papel benéfico que, em todas as épocas históricas, têm representado as migrações, as mesclas, as mestiçagens e, segundo, fazem chegar à opinião pública as vantagens trabalhistas, fiscais e culturais que a imigração proporciona a todos nós.

A chegada de novos habitantes pode oferecer vantagens sociais, econômicas e culturais para os centros urbanos, contribuindo para a redução da pobreza e a melhoria do desenvolvimento humano. Processos migratórios impulsionam o mercado de trabalho ${ }^{50}$, geram novas demandas por

\footnotetext{
${ }^{49}$ Enquanto a universalidade diz respeito ao caráter erga omnes dos Direitos Humanos, uma vez que seu titular é o ser humano, não importando qualquer distinção de raça, credo, sexo, nacionalidade, idade, profissão, formação intelectual ou qualquer outro elemento que o distinga; a indivisibilidade fundamenta-se no princípio da não discriminação e na igualdade de tratamento jurídico. Por sua vez, a inalienabilidade relaciona-se à irrenunciabilidade e indisponibilidade dos Direitos Humanos, quer dizer, tais direitos não podem ser transferidos por meio gratuito tampouco por meio oneroso (reporta-se ao seu conteúdo moral, pessoal, individual, inerente à sua condição de pessoa humana) (ANNONI, 2013, p. 32).

${ }^{50}$ Migrantes ambientais fornecem mão-de-obra e fomentam a economia dos países que apresentam altos índices de envelhecimento da população. Nos próximos 15 anos, diversas nações constatarão o declínio de suas forças de trabalho, exigindo o acolhimento de novos habitantes para que a produção de bens e a economia sejam mantidas. A título de exemplo, estima-se que a população em idade ativa (dos 22 aos 66 anos)
} 
bens e serviços, promovem a geração de renda ${ }^{51}$, assim como aumentam as receitas fiscais (OIM, 2018). Como vetores do crescimento econômico e, consequentemente, da criação de novas vagas de trabalho, migrantes ambientais atuam como fontes de inovação e experiência que podem ser aproveitadas para reduzir os impactos de desastres ambientais e impulsionar medidas de adaptação às mudanças climáticas (WARN, ADAMO. 2014, p. 01).

Assim sendo, diversas cidades têm trabalhado no sentido de promover o acolhimento de migrantes ambientais, buscando formas de Ihes fornecer acesso a serviços básicos e de lhes incluir na malha urbana sem a violação de garantias fundamentais. Trata-se de esforços que possuem o "potencial de transformar discursos de políticas migratórias, reconhecendo as contribuições sociais, culturais e econômicas dos migrantes para a vida urbana e possibilitando, ao mesmo tempo, um sentimento de pertencimento em nível urbano" (ARMITH, 2016, p. 03) ${ }^{52}$.

Nesse sentido, a cidade de São Paulo instituiu a Política Municipal para a População Imigrante (Lei Municipal 16.478 de 2016), a qual reitera a manutenção de direitos a todos os migrantes que vivem na cidade. A lei garante a continuidade e ampliação dos serviços existentes e ações de promoção de dos Direitos Humanos e de respeito à diversidade. Enquanto isso, em Nova lorque, todos os migrantes - independentemente do status legal- podem adquirir cartão de identificação que lhes permite acesso a diversos serviços na cidade, como transporte público. Ainda, cidades alemãs estão adequando espaços urbanos desativados para abrigar migrantes recémchegados e seus cidadãos têm desenvolvido projetos voluntários que visam um acolhimento digno e formas sustentáveis de inclusão social (ARMITH, 2016, p. 03).

Cientes disso, após a publicação da Declaração de Nova lorque para Refugiados e Migrantes $^{53}$, em setembro de 2016, Estados-membros da ONU participaram da Conferência das

da Alemanha diminuirá em um quarto (cerca de 13 milhões de indivíduos) entre 2013 e 2040 (UNESCO, 2016, p. 15).

${ }^{51}$ Migrantes ambientais auxiliam suas comunidades de origem por meio do envio de remessas (transferências de dinheiro realizadas por trabalhadores estrangeiros para indivíduos em seus países de origem). Nota-se que a quantidade de dinheiro que os migrantes enviam para as suas famílias nos países em desenvolvimento aumentou 51\% na última década: calcula-se que o valor total enviado pelos migrantes aos países de origem, em 2017, é de aproximadamente U\$ 445 bilhões (UNFPA, 2013, p. 04).

52 Traduzido a partir de: "[...] potential to transform the discourse and politics of migration by recognizing the rich social, cultural and economic contributions of migrants to urban life, while allowing us to imagine the possibilities for migrants to feel a sense of belonging at an urban level".

53 A Declaração de Nova lorque para Refugiados e Migrantes elenca compromissos com vistas à proteção dos Direitos Humanos de todos os migrantes e refugiados, independentemente do status legal, e apresenta diretrizes para o início de negociações que teriam como resultado uma conferência internacional sobre o tema, a ser realizada no decorrer de 2018, e a respectiva adoção de um Pacto Global para migração segura, ordenada e regular. Para a presente pesquisa, importante mencionar que o documento atesta as contribuições dos migrantes para o desenvolvimento econômico e social dos países de acolhimento, bem como reconhece que fatores ambientais também são responsáveis por processos migratórios (ONU, 2016). 
Nações Unidas sobre Habitação e Desenvolvimento Urbano Sustentável (HABITAT III) ${ }^{54}$, realizada um mês depois em Quito com o intuito de discutir políticas globais para a urbanização sustentável e a situação de assentamentos urbanos nas próximas décadas. A Conferência, organizada pelo Programa das Nações Unidas para os Assentamentos Humanos (ONU-Habitat) ${ }^{55}$, teve como objetivo renovar o compromisso político com o desenvolvimento urbano sustentável, discutir a erradicação da pobreza e a redução de assentamentos urbanos informais, assim como identificar novos desafios e avaliar os resultados alcançados pelo Programa até o momento. Ainda, o evento centrou-se na elaboração de um documento não-vinculante em prol do desenvolvimento urbano social, econômico e ambientalmente sustentável capaz de proporcionar moradia adequada para todos (HABITAT III, 2018).

É de ser relevado que HABITAT III foi o primeiro encontro de grande porte da ONU após a adoção da Agenda 2030 e, por isso, propiciou “uma oportunidade única para discutir os desafios de como centros urbanos são planejados e gerenciados a fim de impulsionar o desenvolvimento sustentável e, deste modo, delinear a implementação de novas metas de desenvolvimento global" (HABITAT III, 2018) ${ }^{56}$.

Como resultado, a Nova Agenda Urbana ${ }^{57}$ foi elaborada com o objetivo de repensar o modo como as cidades e aglomerados humanos são projetados, desenvolvidos e administrados. Para tanto, o documento fornece orientações de como projetos urbanos eficazes e sustentáveis podem

\footnotetext{
${ }^{54} \mathrm{O}$ evento foi designado a partir da Resolução 66/207 da Assembleia Geral da ONU, publicada em março de 2012. Ver Resolution adopted by the General Assembly 66/207-Implementation of the outcome of the United Nations Conference on Human Settlements (HABITAT II) and strengthening of the United Nations Human Settlements Programme (UN-HABITAT), disponível em: [http://habitat3.org/wp-content/uploads/A-RES-66207_88100.pdf]

55 Trata-se de Agência da ONU instituída para lidar com assentamentos urbanos e desenvolvimento urbano sustentável. A ONU-Habitat foi estabelecida em 1978, como resultado da Conferência das Nações Unidas sobre Assentamentos Humanos (HABITAT I), realizada em Vancouver no ano de 1976. Na ocasião, governos reconheceram as consequências do rápido processo de urbanização, sobretudo em países em desenvolvimento, e a necessidade de tornar assentamentos urbanos sustentáveis. Seu mandato decorre do plano de ação chamado Agenda Habitat, adotada durante a Segunda Conferência das Nações Unidas sobre Assentamentos Humanos (HABITAT II), realizada em Istambul no ano de 1996. Além de moldar a agenda global de desenvolvimento para os anos seguintes, a Agenda Habitat fornece diretrizes para a criação de assentamentos humanos sustentáveis durante o século XXI, levando em consideração a sua relação com o meio ambiente, direitos humanos, desenvolvimento social, questões demográficas, dentre outros. Foi apenas em 2016, durante a Conferência das Nações Unidas sobre Habitação e Desenvolvimento Urbano Sustentável (HABITAT III), que o tema migração foi incluído na agenda urbana contemporânea. Ver HIII. Disponível em: [http://habitat3.org]. Acesso em: 20 Jun 2018.

${ }^{56}$ Traduzido a partir de: "[...] a unique opportunity to discuss the important challenge of how cities, towns and villages are planned and managed in order to fulfill their roles as drivers of sustainable development and, hence, shape the implementation of new global development goals".

57 O documento articula a busca do desenvolvimento sustentável em cidades e assentamentos urbanos ajudando a concretizar a Agenda 2030 para o Desenvolvimento Sustentável, aprovada em 2015.
} 
aprimorar os resultados de processos de urbanização (HABITAT III, 2015, p. 01).

Além de ser universal em seu escopo e apresentar caráter participativo, inclusivo e centrado na pessoa humana, a Agenda incentiva todos os níveis de governo, assim como a sociedade civil, a tomarem parte dos compromissos pelo desenvolvimento urbano sustentável por meio de diversas ações ${ }^{58}$ : "cada uma delas é uma ferramenta clara, específica e implementável, que permite aos governos, autoridades municipais e organizações diversas da sociedade agirem para inverter a tendência atual descendente na qualidade da urbanização" (CONSELHO DE ARQUITETURA E URBANISMO, 2018).

Outrossim, o documento fundamenta-se no direito à moradia adequada como pressuposto para uma vida digna, sem quaisquer discriminações; no acesso equitativo à água potável e saneamento básico; no acesso igualitário à serviços e bens públicos, tais como alimentação, saúde, educação, infraestrutura, transporte e segurança; na participação e na inclusão social; na redução de riscos de desastres; no crescimento econômico integrado e sustentável; e, por fim, na conservação da biodiversidade e na restauração de ambientes degradados (UN HABITAT, 2017).

Apesar de seu caráter não-vinculante e da ausência de previsão de mecanismos de monitoramento (BEIER, FRITZSCHE, 2017), o documento destaca o respeito ao conjunto de Direitos Humanos dos migrantes e apoia as cidades que thes acolhem com o intuito de auxiliar comunidades e/ou países que atravessam dificuldades de natureza diversas, como conflitos armados e infortúnios ambientais. Ademais, ainda que o movimento populacional para os centros urbanos revele uma variedade de obstáculos, reconhece que tais processos podem trazer significante contribuição social,

\footnotetext{
58 Trata-se de 05 Planos de Ações subdivididos em 35 pontos-chaves. São eles: Política Urbana Nacional (planejamento baseado em projeções populacionais, planejamento regional ao invés de municipal, planejamento de serviços urbanos básicos com padrões mínimos, distinção dos níveis de responsabilidade para todos os níveis de governo, criação de sistemas de governança metropolitana e planos urbanos com força de lei), Legislação Urbana - Regras e Regulamentos (estabelecimento de sistemas de gestão de terras, mecanismos para adquirir, estabelecer e manter espaços públicos; regulação inclusiva dos elementos centrais da urbanização, promoção do equilíbrio de direitos e interesses no desenvolvimento urbano por meio de controle proativo, elaboração de códigos que primem por cidades economicamente vibrantes, inclusivas e seguras; e elaboração de regras urbanas eficazes, eficientes e previsíveis), Planejamento e Projeto Urbano (desenvolvimento de habitações sustentáveis, desenvolvimento de espaços públicos e áreas verdes, promoção da caminhabilidade e do uso da bicicleta, observação das necessidades diárias da população nas políticas de desenvolvimento urbano, planejamento de crise e do crescimento econômico), Economia Urbana e Finanças Municipais (identificação de fontes de financiamento sustentáveis, utilização de instrumentos financeiros locais, maximização de valor, investimentos em serviços urbanos básicos de infraestrutura, planos de investimento que apoiem o crescimento a longo prazo das cidades e opções de financiamento habitacional para moradores de baixa renda ) e Extensões/Renovações Urbanas Planejadas (estabelecimento de espaços públicos adequados, planejamento com base em projeções holísticas, ocupação sustentável de terrenos baldios, favelas e áreas industriais degradadas; prestação equitativa e eficaz de serviços urbanos, oferta de terras para a expansão urbana e restrição da especulação descontrolada de terras) (UN HABITAT, 2017).
} 
econômica e cultural para a vida urbana ${ }^{59}$. A Agenda também reforça a relevância de governos locais para o fortalecimento das relações entre áreas urbanas e rurais, garantindo processos migratórios seguros, ordenados e regulares por meio de políticas migratórias previamente estipuladas ${ }^{60}$.

Assim sendo, a Nova Agenda Urbana ambiciona suprir as necessidades dos migrantes ambientais em áreas urbanas por meio da adoção de um modelo de urbanização inclusivo que leve em consideração todo o processo migratório, isto é, não apenas as dificuldades encontradas no destino final, mas também no local de origem e durante o trânsito. Torna-se possível, deste modo, o resguardo da dignidade da pessoa humana (HABITAT III, 2015, p. 04). Quanto ao seu compromisso com a inclusão social, assim dispõe a ONU-Habitat:

A heterogeneidade é a alma das cidades. Por atrair diferentes pessoas, cidades também devem abranger a diversidade, criando espaços seguros e fazendo da inclusão o seu lema. Quando logram êxito, tornam-se lugares de destaque para o gozo de direitos e oportunidades de forma equitativa, sempre orientadas pelos propósitos e princípios da Carta das Nações Unidas (UN HABITAT, 2017) ${ }^{61}$.

O documento baseia-se nos preceitos da Declaração Universal de Direitos Humanos ${ }^{62}$ ao

\begin{abstract}
${ }^{59}$ Frisa-se que, anteriormente à Nova Agenda Urbana, a Declaração e Programa de Ação adotados durante a III Conferência Mundial das Nações Unidas de Combate ao Racismo, Discriminação Racial, Xenofobia e Formas Conexas de Intolerância, realizada em Durban no ano de 2001, já mencionava as contribuições dos processos migratórios: "Reconhecemos as positivas contribuições econômicas, sociais e culturais feiras pelos migrantes, tanto para os países de origem quanto para os de destino" (UNESCO, 2001).

60 O Artigo 28 da Nova Agenda Urbana assim dispõe: "Comprometemo-nos a assegurar o pleno respeito aos direitos humanos e ao tratamento humano aos refugiados, deslocados e migrantes, independentemente do estatuto legal da sua migração, e apoias as cidades que lhes acolhem no espírito da cooperação internacional, considerando as circunstâncias nacionais, reconhecendo que, apesar do grande movimento populacional para vilas e cidades revelar uma variedade de desafios, também pode trazer significante contribuição social, econômica e cultural para a vida urbana. Comprometemo-nos, ademais, a reforçar as sinergias entre a migração internacional e o desenvolvimento a níveis global, regional, nacional, subnacional e local, assegurando a migração segura, ordenada e regular por meio de políticas de migração planejadas e bem geridas e a apoiar as autoridades locais no estabelecimento de estruturas que permitam a contribuição positiva de migrantes às cidades e reforcem os vínculos urbano-rurais" (HABITAT III, 2018)

${ }^{61}$ Traduzido a partir de: "[...] Heterogeneity is the lifeblood of cities. Cities attract different people and must also embrace diversity, create a safe space for it and make inclusion their mantra. When they succeed in doing so, cities are preeminent places for the enjoyment of equal rights and opportunities, as well as their fundamental freedoms, guided by the purposes and principles of the Charter of the United Nations".

62 Princípios universais de Direitos Humanos que podem ser aplicados aos migrantes ambientais também são encontrados nas seguintes convenções internacionais: Convenção Internacional sobre a Eliminação de Todas as Formas de Discriminação Racial (1965), Pacto Internacional de Direitos Civis e Políticos (1966), Pacto Internacional dos Direitos Econômicos, Sociais e Culturais (1966), Convenção sobre a Eliminação de Todas as Formas de Discriminação contra a Mulher (1979), Convenção Internacional sobre os Direitos da Criança (1989), Convenção Internacional sobre os Direitos das Pessoas com Deficiência (2006), assim como a Convenção n. 111 sobre Discriminação em matéria de Emprego e Profissão da Organização Internacional do Trabalho (OIT) (1958).
\end{abstract}

Revista de Direito da Cidade, vol. 11, no 3. ISSN 2317-7721. pp. 304-346 
reconhecer as garantias fundamentais de todos aqueles que migram, independentemente de seu status legal ${ }^{63}$. Nesse contexto, "uma abordagem urbana pautada em Direitos Humanos exige a cooperação de diversos atores, todos guiados por preceitos democráticos que permitam a participação, a liderança responsável, a transparência, a não-discriminação, o empoderamento e o Estado de Direito" (UNESCO, 2016, p. 08) 6465.

Merece destaque, ainda, a menção ao direito à cidade: prerrogativa de todos os habitantes, sejam eles presentes ou futuros, de ocupar, usar e promover o desenvolvimento de centros urbanos justos, inclusivos e sustentáveis. A cidade torna-se, portanto, um bem comum essencial à qualidade de vida da população e implica responsabilidades, tanto dos governos quanto das pessoas, no que tange a reivindicação, defesa e operacionalização desse direito (HABITAT III, 2016).

Compartilha-se uma visão de cidade para todos no que tange à fruição de suas facilidades, isto é, "o uso equitativo de centros urbanos de acordo com os princípios da sustentabilidade, democracia, equidade e justiça social" (HABITAT III, 2016) ${ }^{66}$. Isso possibilitaria a inclusão dos que nela habitam, sejam de gerações presentes ou futuras, sem discriminações de qualquer ordem, bem como o desenvolvimento de centros urbanos e assentamentos humanos justos, seguros, saudáveis, acessíveis, resilientes e sustentáveis para fomentar prosperidade e qualidade de vida para todos.

A Agenda incluiu os seguintes elementos que fazem referência ao direito à cidade: uma visão abrangente do território, o respeito aos Direitos Humanos e a equidade de gênero, a função social da terra e a captura do valor gerado pelo desenvolvimento urbano, a garantia do envolvimento da cidadania e sociedade no desenho, implementação, monitoramento e avaliação de políticas públicas e orçamentos; a coordenação dentro e entre as esferas de governo, reconhecimento da contribuição do setor informal à economia urbana, assim como o compromisso para a gestão responsável e

63 UNITED NATIONS CONFERENCE ON HOUSING AND SUSTAINABLE URBAN DEVELOPMENT. HABITAT III ISSUE PAPERS: Migration and refugees in urban areas. New York: HABITAT III (H-III), 2015. p. 04.

${ }^{64}$ Traduzido a partir de: "[...] a human rights-based approach to the city entails multi-stakeholder cooperation guided by principles of democracy, participation, responsible leadership, transparency, accountability, nondiscrimination, empowerment and the rule of law".

65 Nesse contexto, a nova versão do Projeto de Convenção Internacional por um Estatuto de Deslocados Ambientais, publicado em abril de 2018 pelo Centro de Pesquisas Interdisciplinares em Direito Ambiental e Urbanismo (CRIDEAU) e liderado pelo Professor Michel Prieur, atesta que os chamados deslocados ambientais têm direito à assistência em todas as fases do deslocamento forçado - não apenas durante, mas também após a iminência de um desastre ambiental -, incluindo a chegada em áreas urbanas. Ademais, todos os deslocados ambientais devem ter acesso à saúde, à educação, à água potável e demais alimentos, bem como às mesmas condições de trabalho que outros trabalhadores. Da mesma forma, a manutenção dos direitos civis e políticos, da personalidade jurídica e das especificidades culturais - tais como a religião e o idioma - devem ser preservados. O documento menciona, ainda, a imprescindibilidade de moradias salubres e seguras, podendo cada indivíduo escolher livremente seu local de residência (CRIDEAU, 2018).

66 Traduzido a partir de: "[...] the equitable use of cities according to principles of sustainability, democracy, equity and social justice". 
sustentável dos recursos naturais, energéticos, patrimoniais e culturais (ALOMAR, 2017, p. 06).

Roborando o assunto, o relatório intitulado Right to the city and cities for all, elaborado durante as reuniões preparatórias ao HABITAT-III, reconhece migrantes, dentre os quais se incluem os ambientais, como importantes atores sociais:

[...] contrário à crença popular, refugiados e migrantes são propagadores de oportunidades para as comunidades de acolhimento, uma vez que carregam consigo novas habilidades, conhecimentos, redes de contato e mão-de-obra qualificada, urgente em países cuja população encontra-se em processo de envelhecimento. Trazem, ademais, diversidade cultural, social e religiosa e contribuem para o progresso não apenas das cidades, mas também para o desenvolvimento de suas regiões de origem (HABITAT III, 2016) ${ }^{67}$.

Ao constatar que processos migratórios são fundamentais para a diversidade cultural de centros urbanos, o estudo preliminar destaca a importância da convivência harmoniosa e respeitosa de diversos grupos sociais. Para tanto, há que se falar no combate à discriminação e segregação, o qual, do ponto de vista urbano, deve ser traduzido em bairros de uso misto, no acesso igualitário a serviços públicos, dentre outros. O direito à cidade valoriza, deste modo, "as diferenças, visto que considera a diversidade sociocultural um componente que desempenha papel fundamental no desenvolvimento da vida urbana"68.

Merece destaque, ainda, a Declaração de Pretória, divulgada após reunião temática sobre assentamentos urbanos informais que também antecedeu a realização do HABITAT III. O documento sugere que os três níveis de governo - nacional, estadual e municipal - devem integrar, explicita e sistematicamente, a migração nos procedimentos de planejamento urbano, aproveitando as oportunidades que tal fenômeno proporciona e administrando possíveis obstáculos (HABITAT III, 2016). Tais processos devem considerar o grau de desenvolvimento e as diferentes realidades nacionais, assim as respectivas capacidades dos diferentes grupos que compõem os aglomerados humanos.

Assim posta a questão, a presente pesquisa parte para uma breve análise das chamadas capacidades na teoria ética e econômica de Amartya Sen, a qual se aproxima da realidade dos migrantes ambientais nos grandes centros urbanos contemporâneos.

\footnotetext{
${ }^{67}$ Traduzido a partir de: "Yet refugees and migrants, for example, contrary to popular belief, are vectors of opportunities for the hosting society, as they bring new skills and knowledge, new networks of contacts and new workforce, a critical need for some countries with ageing population. They also bring cultural, social, and religious diversity to the city, and greatly contribute to the wealth of the cities and of their regions of origin". ${ }^{68}$ Traduzido a partir de: "[...] Valorization of differences, while looking at sociocultural diversity as a component of urban life that plays a key role in unlocking social potential".
} 
Com o intuito de avaliar o desenvolvimento de uma nação e medir a justiça de seus arranjos sociais no estabelecimento de um rol mínimo de garantias que devem ser viabilizados aos seus cidadãos, o professor indiano relaciona as questões de igualdade e liberdade formal asseguradas pelos Estados às reais liberdade ${ }^{69}$ usufruídas pelas populações, quer dizer, as possibilidades substantivas de tais indivíduos viverem de acordo com seus anseios (SEN, 2011, p. 325-350).

Para tanto, o enfoque das capacidades ${ }^{70}$ proposto por Sen tem como objetivo mensurar os níveis de desenvolvimento e de qualidade de vida da população de uma determinada área, possibilitando a implementação de políticas públicas que visem reduzir as causas de iniquidades humanas ou, neste caso, promover a inclusão dos migrantes ambientais nas cidades (SEN, 2011, p. 325-350).

Enfatiza-se que o tratamento dado ao ser humano não deve se restringir ao rol de direitos e obrigações outorgados pelo Estado, mas também abarcar meios de torná-lo agente do seu próprio destino. É dizer, não basta promover o acolhimento desses grupos de pessoas, há que se falar na qualificação dessas para que possam viver de acordo com suas próprias concepções do que seria melhor (SEN, 2011, p. 325-350).

Nessa perspectiva, o migrante ambiental só pode ser considerado integrado/incluído em uma determinada comunidade quando é capaz de viver de acordo com os seus desejos. Além de possuir direitos formais, deve ter acesso a todos os meios materiais (como habitação, saneamento básico, acesso à água potável e saúde) e imateriais (como educação e direitos políticos) necessários para concretizá-los (SEN, 2011, p. 325-350).

Assim sendo, planejamentos urbanos sustentáveis devem ser medidos não apenas pelo que as pessoas realizam, mas sobretudo pelas liberdades que possuem de cultivar um estilo de vida desejado, pautado na efetiva concretização das garantias fundamentais da pessoa humana. É dizer, "a questão de saber se uma pessoa é capaz de produzir os objetos de sua escolha arrazoada é crucial para a ideia de liberdade que está sendo buscada aqui, da qual é parte a noção de capacidade" (SEN, 2011, p. 335).

De acordo com Sen, o verdadeiro caminho do desenvolvimento se dá pela eliminação de todas as privações de liberdade que limitam as escolhas e oportunidades dos indivíduos de

\footnotetext{
69 Liberdade, aqui, "não é definida apenas com relação ao que uma pessoa é capaz de fazer em determinada esfera, mas também inclui a exigência de que outros não possam eliminar essa capacidade mesmo que queiram fazê-lo" (SEN, 2011, p. 339).

70 Capacidade, nesse contexto, designa-se não apenas como a possibilidade de exercer alguma atividade, mas também "em uma perspectiva em cujos termos as vantagens e desvantagens de uma pessoa podem ser razoavelmente avaliadas" (SEN, 2011. p. 331).
} 
recomeçarem suas vidas em outras localidades de forma digna.

Partindo para uma outra abordagem, cumpre mencionar a mensagem do Papa Francisco ${ }^{71}$ para a celebração do Dia Mundial da Paz ${ }^{72}$, no início de 2018. O texto, intitulado Migrantes e refugiados: homens e mulheres em busca de paz, enfatiza que, inobstante o peso do acolhimento dos migrantes recém-chegados aos centros urbanos, a dignidade humana deve ser reconhecida a todos de forma indistinta (PAPA FRANCISCO, 2018, p. 02).

De acordo com o Pontífice, a crescente presença de pessoas de origens diversas coabitando nas mesmas áreas urbanas pode tornar-se um fator sociocultural positivo e criativo. Ao ver nas migrações uma "oportunidade para construir um futuro de paz" (PAPA FRANCISCO, 2018, p. 03), afirma que "detendo-se sobre os migrantes e refugiados, esse olhar saberá descobrir que eles não chegam de mãos vazias: trazem uma bagagem feita de coragem, capacidades, energias e aspirações, para além dos tesouros das suas culturas nativas" (PAPA FRANCISCO, 2018, p. 04), enriquecendo a vida dos locais que os acolhem.

Além de reconhecer os benefícios da migração, uma vez que aqueles que chegam acabam por impulsionar a economia dos locais de acolhida, o Papa Francisco também reforça a imprescindibilidade dos preceitos do Estado de Direito em relação aos migrantes e refugiados no sentido de evitar tratamentos desumanos diante de conflitos armados ${ }^{73}$.

O Pontífice aponta quatro etapas para a recepção satisfatória dos migrantes nos centros urbanos: acolher, proteger, promover e integrar (PAPA FRANCISCO, 2018, p. 04). Enquanto acolher faz apelo à premissa de ampliar as possibilidades de estadia legal e equilibrar tensões sociais com a tutela dos Direitos Humanos, proteger lembra o dever de respeitar ativamente a dignidade de quem

\footnotetext{
${ }^{71}$ Líder da Igreja Católica Apostólica Romana e atual Chefe de Estado do Vaticano, sucedendo ao Papa Bento XVI, que abdicou ao papado em fevereiro de 2013.

${ }^{72}$ O Dia Mundial da Paz é comemorado anualmente no dia 01 de janeiro e, ainda que não se restrinja apenas aos católicos, foi criado pelo Papa Paulo VI, em 1967.

${ }^{73}$ A assertiva relaciona-se ao ODS 16 - Paz, justiça e instituições eficazes, que visa promover sociedades pacíficas e inclusivas para o desenvolvimento sustentável, proporcionar o acesso à justiça para todos e construir instituições eficazes, responsáveis e inclusivas em todos os níveis. Para tanto, o objetivo apresenta dez metas: reduzir todas as formas de violência e as taxas de mortalidade; acabar com abuso, exploração, tráfico e todas as formas de violência e tortura contra crianças; promover o Estado de Direito, em nível nacional e internacional, e garantir a igualdade de acesso à justiça para todos; reduzir os fluxos financeiros e de armas ilegais, reforçar a recuperação e devolução de recursos roubados e combater todas as formas de crime organizado; reduzir a corrupção e suborno em todas as suas formas; desenvolver instituições eficazes, responsáveis e transparentes; garantir a tomada de decisão responsiva, inclusiva, participativa e representativa; ampliar e fortalecer a participação dos países em desenvolvimento nas instituições de governança global; fornecer identidade legal para todos, incluindo o registro de nascimento; e assegurar o acesso público à informação e proteger as liberdades fundamentais. Ver Sustainable Development Knowledge Platform - Sustainable Development Goal 16. Disponível em: [https://sustainabledevelopment.un.org/sdg16]. Acesso em: 20 Jun 2018.
} 
busca guarida e impedir a sua exploração. Por sua vez, promover alude ao apoio para o desenvolvimento humano integral, em especial a educação de crianças e jovens, em todos os níveis de ensino. Enfim, integrar significa permitir que todos participem plenamente da vida na sociedade que os recebe, "a partir de uma dinâmica de mútuo enriquecimento e fecunda colaboração na promoção do desenvolvimento humano integral das comunidades locais" (PAPA FRANCISCO, 2018, p. 04).

Assim sendo, a fim de assegurar cidades acolhedoras para os migrantes ambientais, tornase necessário não apenas promover o acesso a bens e serviços básicos, a igualdade de tratamento e de oportunidades, a proibição de discriminação e campanhas contra racismo e xenofobia; mas também reconhecê-las como lugares dinâmicos e propulsores de multiculturalidade. Ademais,

Melhores políticas, maior engajamento e apoio adequado aos governos locais são necessários para que cidades possam se beneficiar da migração. Para permitir o suporte digno àqueles que chegam em larga escala, governos, em todos os níveis, precisam empoderar atores locais e contribuir efetivamente para a promoção de políticas que, concomitantemente, sejam capazes de garantir direitos fundamentais aos migrantes e melhorar a qualidade de vida de todos aqueles que habitam centros urbanos (OIM, 2018) ${ }^{74}$.

Por todo o exposto, infere-se que os centros urbanos podem vir a estimular o desenvolvimento sustentável e proporcionar melhores condições socioeconômicas não apenas para seus habitantes, mas também para todos aqueles que migram em sua direção. Há que se falar, deste modo, na elaboração e na implementação de políticas abrangentes, equilibradas e inclusivas, isto é, que abarquem todos os setores da comunidade de igual forma.

Resultados positivos dependem de uma série de fatores, incluindo desde a natureza das instituições e dos processos democráticos locais até a disponibilidade de recursos e a capacidade de organização e articulação de demandas pelos migrantes ambientais (AVIS, 2016, p. 06). Nesse sentido, "a história demonstra que a diversidade é um desafio para a inclusão sustentável de diferentes grupos em cidades. Lidar com essa diversidade pode exigir a criação de sistemas que garantam a equidade, segurança, bem-estar econômico e identidade cultural dos de grupos marginalizados" (HABITAT III, 2016), incluindo os migrantes ambientais.

\footnotetext{
74 Traduzido a partir de: "We need better policies, more engagement and adequate support for local governments to harness the significant benefits from migrants in our cities. In order to enable dignified support of migrants who come in large numbers, governments at all levels need to empower local actors and collaborate effectively to promote people-centered integration policies which both protect the human rights of migrants, and also to improve the quality of life for all those living in cities".
} 
A migração ambiental já não é considerada como algo novo pela comunidade internacional. A novidade parece residir na complexidade dos desafios que tal fenômeno enseja às nações. $O$ planejamento urbano de cidades impõe desafios à dinâmica de uma sociedade que se propõe a alcançar o desenvolvimento sustentável e a igualdade material por meio de políticas ultrapassadas e repletas de lacunas.

Em verdade, a soberania estatal acaba por se estabelecer como justificativa para a delimitação de compromissos em âmbito internacional e reflete a falta de vontade política dos países em avançar no tópico, mantendo a autoridade suprema sobre seus territórios 75 . Isto é, "por se tratar de um aspecto de caráter mais político do que legal, os avanços dos instrumentos que visam a proteção dos migrantes ambientais esbarram em pouca disposição dos Estados em aderirem a maiores compromissos" (NUNES, 2018, p. 281).

Indaga-se, desde logo, as bases em que os Estados-nação foram concebidos. Ao definir fronteiras nacionais, ignorou-se o fato de que conflitos também podem englobar questões externas e, sobretudo, que interações entre comunidades humanas são perenes e demonstram a interdependência entre indivíduos na sociedade global. Assim sendo, "Estados devem se adaptar às transformações e desafios correspondentes no mundo sobre territórios, direitos humanos e mobilidade" (NUNES, 2018, p. 280).

Somado a isso, reitera-se que Estados modernos não hesitam em expor o caráter individualista de suas preferências. Tendo em vista que optar por suas prioridades não é tido como algo imoral, nações assumem uma ética minimalista e intermitente, assim como "uma forma de solidariedade compatível com o primado do ego de seus governos" (NUNES, 2018, p. 280). Nesse contexto, Lipovetsky $(2005$, p. 109) denota que, em uma sociedade pós-moralista, há o desejo de auxiliar outras nações e grupos específicos de pessoas, como os migrantes ambientais, mas sem que haja comprometimento em excesso, ou seja, "generosidade contanto que seja algo fácil e distante, sem ligação com esta ou aquela forma superior de renúncia".

Enquanto países fracassam ao se ater/limitar à questões relacionadas à soberania ${ }^{76} \mathrm{e}$ ao fechamento de fronteiras nacionais, cidades apresentam posição de maior autonomia. Quando

\footnotetext{
75 Comumente, Estados tratam processos migratórios de cunho ambiental como questões humanitárias. Torna-se possível, assim, que países se coloquem na condição de doadores por meio de atos solidários sem que isso implique em uma obrigação (NUNES, 2018. p. 282).

${ }^{76}$ Frisa-se que a soberania, como exercício do poder do Estado legitimado pela ordem jurídica, só se legitima e se justifica se estiver em consonância com a dignidade da pessoa humana. Deste modo, soberania deve ser entendida não como um direito em si, mas como uma responsabilidade: "A soberania estatal, em seu sentido mais básico, está sendo redefinida - nomeadamente pelas forças da globalização e da cooperação
} 
defrontadas com adversidades, essas se mostram mais abertas à políticas e respostas cosmopolitas, bem como à adaptação a novas realidades.

De acordo com Beck, como centros urbanos vivenciam o choque de riscos globais - como os efeitos adversos das mudanças climáticas - de forma cotidiana, tais localidades são pioneiras em assumir o desafio de encontrar respostas para uma modernidade que se depara constantemente com novas contratempos (BECK, 2016, p. 180). Portanto, cidades se qualificam como atores que desempenham papel de relevância no que tange o combate às mudanças climáticas e as migrações ambientais.

Como cidades entre si podem acatar deliberações que se tornam vinculantes, elas ganham notoriedade como tomadoras de decisões em processos de elaboração de regulamentos internacionais. Ademais, não se pode perder de vista que elas estão sujeitas às práticas democráticas tradicionais: como exemplo, prefeitos são reeleitos com base no progresso alcançado no meio de processos de urbanização desordenados e na capacidade de mantê-las funcionando de forma sustentável.

Portanto, resta saber se os centros urbanos recuperarão papel desempenhado antes do surgimento dos Estados-nação no que tange a tomada de decisões políticas. Apesar de preceitos políticos terem surgido e se desenvolvido nas polis, no decorrer dos últimos séculos, as cidades submeteram-se à regimes monárquicos, impérios e Estados de Direito para reproduzir ordem social e política. Não se pode perder de vista que "é a polis que torna os homens iguais por meio da lei e dos direitos, e é neste sentido que a política institui a pluralidade humana e um mundo comum" (MELO, 2015, p. 148).

Como o sistema vigente não apresenta respostas satisfatórias para a migração ambiental e demais riscos oriundos das mudanças climáticas, as cidades podem, novamente, retomar e desempenhar papel de relevância.

\section{CONCLUSÕES}

Apesar da mobilidade humana em razão de infortúnios ambientais não ser um fato inédito na história da humanidade, tal fenômeno tem se intensificado em razão dos efeitos adversos das mudanças climáticas. Constatou-se, diante disso, que o enquadramento dessas pessoas na concepção tradicional de refugiado resta inviabilizado em razão em razão da dificuldade em

internacional. Estados atualmente são amplamente entendidos como instrumentos a serviço de seus povos, e não o contrário" (ALVES, 2018, p. 29).

Revista de Direito da Cidade, vol. 11, no 3. ISSN 2317-7721. pp. 304-346 336 
qualificar a devastação do meio ambiente como persecução, bem como em encaixá-la em um dos fundamentos que configuram o instituto do refúgio. Assim, foi na tentativa de alargamento dessa definição que os delineamentos para a conceitualização dessa categoria de pessoas emergiram, todos devidamente abordados no decorrer da presente pesquisa.

Como grande parte dos migrantes ambientais permanece dentro de suas fronteiras nacionais e os deslocamentos humanos geralmente ocorrem de áreas rurais para centros urbanos, debates sobre os impactos dos fluxos migratórios e a dinâmica dos migrantes ambientais nas relações sociais, econômicas, políticas e culturais das cidades passaram a ganhar destaque. Apesar da urbanização ter a (i)migração como uma de suas características centrais, verificou-se que quando tal processo acontece de forma rápida e desordenada, a chegada de novos habitantes aos centros urbanos é vista como sendo responsável pela falta de moradia e infraestrutura, pela precariedade na prestação de serviços, assim como pela intensificação da instabilidade social.

Ao acentuar a emissão de GEE na atmosfera, áreas urbanas tornam-se suscetíveis e incapazes de lidar com as consequências das mudanças climáticas de forma satisfatória, expondo milhões de habitantes, na sua maioria moradores de assentos informais ou pertencentes a grupos vulneráveis, a diversos desastres ambientais. Nesse contexto, restou evidenciado que além dos desafios enfrentados pelos grandes centros urbanos em razão das alterações do clima, os migrantes ambientais defrontam-se ainda com outros obstáculos oriundos do acelerado processo de urbanização. A situação vulnerabilidade e a constante deterioração do meio ambiente ensejam crises socioambientais sem precedentes, acometem o bem-estar social e econômico e, sobretudo, provocam a violação dos direitos humanos dos recém-chegados.

Diante disso, atestou-se que planejamento e governança urbana contribuem para o desenvolvimento sustentável não apenas no que diz respeito ao crescimento econômico sustentado e à proteção ambiental, mas também quanto à promoção de um desenvolvimento social inclusivo. Foi nesse contexto que os ODS e, em especial o Objetivo 11 - Tornar as cidades e os assentamentos humanos inclusivos, seguros, resilientes e sustentáveis, foram analisados.

Apesar de endossar um objetivo que aborda especificamente as cidades e reconhecer os centros urbanos como forças transformadoras do desenvolvimento sustentável, notou-se que o ODS 11 não faz referências ao papel desempenhado e às contribuições trazidas pelos migrantes ambientais a todo processo de urbanização: o acolhimento desses indivíduos pode oferecer vantagens sociais, econômicas e culturais para as cidades, contribuindo para a redução da pobreza e a melhoria do desenvolvimento humano. 
Analisou-se, em razão disso, a Nova Agenda Urbana. Elaborada com o objetivo de repensar o modo como as cidades e aglomerados humanos estão sendo projetados, desenvolvidos e administrados, o documento destaca o respeito ao conjunto de Direitos Humanos - sobretudo o direito à cidade - dos migrantes e apoia as áreas urbanas que lhes acolhem com o intuito de auxiliar comunidades e/ou países que atravessam dificuldades de natureza diversas, como conflitos armados e infortúnios ambientais. Observou-se, ainda, que a Agenda reconhece que processos migratórios podem trazer significantes contribuições para a vida urbana.

Deste modo, percebeu-se que, enquanto a ONU-Habitat reconhece as contribuições trazidas pelos migrantes às cidades na sociedade contemporânea, os ODS fornecem às nações um novo roteiro político para a promoção do desenvolvimento socioeconômico até o ano de 2030.

Assim sendo, a fim de assegurar cidades acolhedoras para os migrantes ambientais, tornase necessário não apenas promover o acesso a bens e serviços básicos, a igualdade de tratamento e de oportunidades, a proibição de discriminação e campanhas contra racismo e xenofobia; mas também reconhecê-las como lugares dinâmicos e propulsores de multiculturalidade. Logo, os centros urbanos podem vir a estimular o desenvolvimento sustentável e proporcionar melhores condições socioeconômicas não apenas para seus habitantes, mas também para todos aqueles que migram em sua direção.

Concluiu-se, por todo o exposto, que a migração ambiental já não é considerada como algo novo pela comunidade internacional. A novidade parece residir na complexidade dos desafios que tal fenômeno enseja às nações. O planejamento urbano de cidades impõe desafios à dinâmica de uma sociedade que se propõe a alcançar o desenvolvimento sustentável e a igualdade material por meio de políticas ultrapassadas e repletas de lacunas.

\section{REFERÊNCIAS BIBLIOGRÁFICAS}

ALOMAR, J. S. C. O direito à cidade e a Nova Agenda Urbana da ONU: Perspectivas para a inovação urbanística no contexto do fortalecimento do neoliberalismo. XVII ENANPUR: Perspectivas para o planejamento urbano e regional, São Paulo, 2017.

ALVES, A. L. A. Refúgio e Soberania Estatal: "Refugiados Ambientais. In JUBILUT, L. L. [et al.]. Refugiados Ambientais. Boa Vista: Editora da UFRR, 2018. 
AMRITH, M. Cities for All? Migration and the New Urban Agenda. United Nations University, 2016. Disponível em: [https://unu.edu/publications/articles/cities-for-all-migration-and-the-new-urbanagenda.html]. Acesso em: 15 Mar. 2018.

ANNONI, D. O direito internacional dos refugiados e o Brasil. Curitiba, PR: Juruá, 2013.

AVIS, W. R. Urban Governance. Birmingham, UK: GSDRC, University of Birmingham, 2016.

BECK, U. The metamorphosis of the world. Cambridge, UK: Polity Press, 2016.

BEIER, R.; FRITZSCHE, J. Refugee and the city: UN-Habitat's New Urban Agenda. Forced Migration Review, n. 55, 2017. Disponível em: [http://www.fmreview.org/shelter]. Acesso em: 15 Mar. 2018.

BOBBIO, N. Elogio da serenidade e outros ensaios. Tradução de Marco Aurélio Nogueira. São Paulo: Editora Unesp, 2002.

BRADBROOK, A.; OTTINGER, R. Energy law and sustainable development. Geneva, Switzerland: IUCN, 2003.

CASTLES, S. The age of migration. New York: Guilford Press, 1993.

CENTRE DE RECHERCHE INTERDISCIPLINAIRE EN DROIT DE L'ENVIRONNEMENT ET L'URBANISME CRIDEAU. Projet de Convention Relative au Statut International des Déplaces Environnementaux. Limoges : Cournil Ch., 2009.

CHAWLA, A. Climate-induced migration and instability: the role of city governments. OEF Research: one earth future, 2017.

CONSELHO DE ARQUITETURA E URBANISMO DO BRASIL. Conheça os 30 pontos fundamentais da Nova Agenda Urbana. Disponível em: [http://www.caubr.gov.br/conheca-os-30-pontos-de-acaofundamentais-para-a-implementacao-da-nova-agenda-urbana/]. Acesso em: 05 Ago. 2018. 
FERNANDES, E. A. Meio ambiente e direitos humanos: o deslocamento de pessoas por causas ambientais agravadas pelas mudanças climáticas. Curitiba: Juruá, 2014.

INTERGOVERNMENTAL PANEL ON CLIMATE CHANGE (IPCC). Working Group I Contribution To The IPCC Fifth Assessment Report. Climate Change 2013: the Physical Science Basis. Sweden: 2013.

Global Warming of $1,5^{\circ} \mathrm{C}$ : an IPCC special report on the impacts of global warming of $1,5^{\circ}$ C above pre-industrial levels and related global greenhouse gas emission pathways, in the context of strengthening the global response to the threat of climate change, sustainable development, and efforts to eradicate poverty. República da Coréia: Summary for Policymakers, 2018.

CLIMATE CHANGE: The 1990 and 1992 IPCC Assessments. IPCC First Assessment Report Overview and Policymaker Summaries and 1992 IPCC Supplement. Canada, 1990.

INTERNAL DISPLACEMENT MONITORING CENTRE (IDMC). GRID 2018: Global Report on Internal Displacement. Switzerland: Norwegian Refugee Council (NRC) and Internal Displacement Monitoring Centre (IDMC), 2018.

ORGANIZAÇÃO INTERNACIONAL PARA AS MIGRAÇÕES (OIM). Migration, environment and climate change: Assessing the evidence. Suíça: IOM, 2009.

UN-HABITAT Event recognizes contribution of migrants to cities. Disponível em: [https://www.iom.int/news/un-migration-agency-un-habitat-event-recognize-contributionmigrants-cities]. Acesso em: 15 Mar. 2018.

IONESCO, D.; MOKHNACHEVA, D.; GEMENE, F. The Atlas of environmental migration. London and New York: Routledge - Taylor and Francis Group, 2017.

FARENA, M. N. F. C. DIREITOS HUMANOS DOS MIGRANTES: Ordem Jurídica Internacional e Brasileira. Curitiba, PR: Juruá, 2012.

GIDDENS, A. A terceira via: reflexões sobre o impasse político atual e o futuro da socialdemocracia. Tradução de Maria Luiza Borges. Rio de Janeiro: Record, 1999. 
HERRERA FLORES, J. A (Re)invenção dos Direitos Humanos. Florianópolis, SC: 2009.

JACOBSON, J. L. Environmental Refugees: a yardstick of habitability. Worldwatch Paper 86. Washington, D.C.: Worldwatch Paper 86, 1998.

JURAS, L. A. G. M. Aquecimento global e mudanças climáticas: uma introdução. Brasília: Biblioteca Digital da Câmara dos Deputados, 2008.

LEAL-ARCAS, R. Climate change and international trade. Cheltenham, UK: Edward Elgar Publishing Limited, 2013.

LEHMAN, J. Environmental refugees: the construction of a crisis. Prepared for the UHU-EHS Summer Academy, 2009.

LIPOVETSKY, G. A sociedade pós-moralista: o crepúsculo do dever e a ética indolor dos novos tempos democráticos. Tradução de Armando Braio Ara. São Paulo: Manole, 2005.

MARÇAL. T. Governança Urbana e o Desenvolvimento Sustentável das Cidades. 5th German-Brazilian Dialogue on Science, Research and Innovation: The city of tomorrow - Tackling urban challenges and opportunities. Disponível em: [http://dwih.com.br/sites/default/files/imce_default/...]. Acesso em: 05 Ago. 2018.

MELO, M. P. Entre igualdade e diversidade: globalização, migrações, direitos humanos e relações interculturais. In PRONER, C. (coord.). MIGRAÇÕES: Políticas e Direitos Humanos sob as perspectivas do Brasil, Itália e Espanha. Curitiba: Juruá, 2015.

MEYER, W. B. THE ENVIRONMENTAL ADVANTAGES OF CITIES: Countering Commonsense Antiurbanism. Cambridge: The MIT Press, 2013.

MINISTÉRIO DO PLANEJAMENTO, DESENVOLVIMENTO E GESTÃO. Relatório nacional voluntário sobre os Objetivos do Desenvolvimento Sustentável. Brasil, 2017. Disponível em: [https://sustainabledevelopment.un.org/]. Acesso em: 15 Mai 2018. 
MURILLO, F. Migrants and rapid urbanization: a new agenda for humanitarian and development urban planning? New York: United Nations Department of Economic and Social Affairs (UN-DESA), 2017.

MYERS, N. Environmental exodus: an emergent crisis in the global arena. Washington: Project of the Climate Institute, 1995.

NAÇÕES UNIDAS NO BRASIL (ONUBR). OBJETIVO 11: Tornar as cidades e os assentamentos humanos inclusivos, seguros, resilientes e sustentáveis. Disponível em: [https://nacoesunidas.org/pos2015/ods11/]. Acesso em: 15 Mai 2018.

NUNES, P. P. M. Políticas de Proteção aos Deslocados Ambientais no Sistema Internacional: reflexões sobre o papel da soberania estatal. In: JUBILUT, L. L.; FRINHANI, F. M. D.; LOPES, R. O. (org.). Migrantes forçados: conceitos e contextos. Boa Vista, RR: Editora da UFPP, 2018.

ORGANIZAÇÃO DAS NAÇÕES UNIDAS PARA A EDUCAÇÃO, A CIÊNCIA E A CULTURA (UNESCO). Declaração e Programa de Ação adotados na III Conferência Mundial de Combate ao Racismo, Discriminação Racial, Xenofobia e Formas Conexas de Intolerância. Durban, África do Sul: 2001. Disponível em: [https://www.oas.org/]. Acesso em: 05 Ago. 2018.

PAINEL BRASILEIRO DE MUDANÇAS CLIMÁTICAS (PBMC). Mudanças Climáticas e Cidades: Relatório Especial do Painel Brasileiro de Mudanças Climáticas. Rio de Janeiro: PBMC, 2016.

PAPA FRANCISCO. Carta Encíclica Laudato Si': Sobre o cuidado da casa comum. Vaticano: Edições Paulinas, 2015.

Mensagem do Santo Padre Francisco para a celebração do 51 Dia Mundial da Paz. Migrantes e Refugiados: homens e mulheres em busca de paz. Vaticano: Libreria Editrice Vaticana, 2018. p. 02. Disponível em: [http://w2.vatican.va/content/francesco/pt/messages]. Acesso em: 15 Mar 2018. 
PIGUET, E. Climate Change and Forced Migration. New Issues in Refugee Search, Research Paper, n. 153, p. 1-13, 2008.

PREPARATORY COMMITTEE FOR THE UNITED NATIONS CONFERENCE ON HOUSING AND SUSTAINABLE URBAN DEVELOPMENT (HABITAT III). Habitat III thematic meeting on informal settlements. Surabaya, Indonesia: July 2016.

. Policy Paper 1: Right to the city and cities for all. Surabaya, Indonesia: July 2016. Disponível em: [http://habitat3.org/wp-content/uploads/Policy-Paper-1-English.pdf] Acesso em: 05 Ago. 2018.

RAIOL, I. P. C. Ultrapassando fronteiras: a proteção jurídica dos refugiados ambientais. Porto Alegre: Núria Fabris, 2010.

RAMOS, É. P. Refugiados Ambientais: em busca do reconhecimento pelo direito internacional. 2011. 150 f. Tese (Doutorado em Direito) - Faculdade de Direito da Universidade de São Paulo, São Paulo, 2011, p. 76. Disponível em: <http://www.acnur.org/>. Acesso em: 05 Jan 2018.

RAMOS, É. P. Refugiados, migrantes ou deslocados ambientais: uma abordagem inspirada na proteção do meio ambiente e nos direitos humanos. In: LEITE, José Rubens Morato (Coord.). Manual de Direito Ambiental. $1^{\text {a }}$ ed. São Paulo: Saraiva, 2015.

RENAUD, F.; et al. Control, adapt or flee: how to face environmental migration? Alemanha: United Nations University for Environment and Human Security (UNU-EHS), 2007.

ROBINSON, N. A. Environmental Law: is an obligation erga omnes emerging? Permanent Mission of Colombia to the United Nations: Panel Discussion at the United Nations regarding the Advisory Opinion (OC-23/17) of the Inter-American Court of Human Rights of 15 November 2017. Disponível em:

[https://www.iucn.org/sites/dev/files/content/documents/2018/environmental_law_is_an_obligati on_erga_omnes_emerging_interamcthradvisoryopinionjune2018.pdf]. Acesso em: 04 Jun 2018. 
ROSENZWEIG, C. et al. Urban Climate Change in Context - Climate Change and Cities: First Assessment Report of the Urban Climate Change Research Network. Cambridge: Cambridge University Press, 2011.

SEN, A. A ideia de justiça. Tradução de Denise Bottmann e Ricardo Doninelli Mendes. São Paulo: Companhia das Letas, 2011.

SERRAGLIO, D. A.SEÉPA proteção dos refugiados ambientais pelo direito internacional: uma análise a partir da teoria da sociedade de risco Dissertação (Mestrado) - Pontifícia Universidade Católica do Paraná, Curitiba, 2014.

THE WORLD BANK GROUP. Guia de Adaptação à Mudança Climática nas Cidades: Sumário Executivo. Washington, DC: The World Bank, 2016.

TIBERGHIEN, F. «Refugiés » écologiques ou climatiques: de nombreuses questions juridiques en suspens. Paris: Association des Revues Plurielles, 2008.

UNITED NATIONS (UN). Resolution adopted by the General Assembly on 19 September 2016: New York Declaration for Refugees and Migrants. Disponível em: [http://www.un.org/en/ga/search/view_doc.asp?symbol=A/RES/71/1]. Acesso em: 15 Mar 2018.

Sustainable Development Knowledge Platform: Sustainable Development Goal 16. Disponível em: [https://sustainabledevelopment.un.org/sdg16]. Acesso em: 20 Jun 2018. . Transforming our world: the 2030 Agenda for Sustainable Development. Disponível em: [https://nacoesunidas.org/pos2015/agenda2030/]. Acesso em: 15 Mai 2018.

United Nations Convention on Climate Change. Rio de Janeiro: UN, 1992. Disponível em: [https://unfccc.int/resource/docs/convkp/conveng.pdf]. Acesso em: 15 Mar 2018.

UNITED NATIONS CONFERENCE ON HOUSING AND SUSTAINABLE URBAN DEVELOPMENT. HABITAT III ISSUE PAPERS: Migration and refugees in urban areas. New York, USA: HABITAT III, 2015. 
Action Framework for Implementation of the New Urban Agenda. New York, 2017. Disponível em: [http://nua.unhabitat.org/AFINUA19thApr.pdf]. Acesso em: 20 Jun 2018.

. HABITAT III (HIII). Quito: HABITAT III (H-III). Disponível em: [http://habitat3.org]. Acesso em: 20 Jun 2018.

New Urban Agenda. Quito: HABITAT III (H-III). Disponível em: [http://habitat3.org/wpcontent/uploads/NUA-English.pdf]. Acesso em: 15 Mar 2018.

UNITED NATIONS EDUCATIONAL, SCIENTIFIC AND CULTURAL ORGANIZATION (UNESCO). Cities welcoming refuges and migrants. Paris: UNESCO, 2016.

UNITED NATIONS HIGH COMMISSIONER FOR REFUGEES (UNHCR). Convention Relating to the Status of Refugees. Geneva, 1951. Disponível em: [http://www.unhcr.org/3b66c2aa10]. Acesso em: 15 Mar 2018.

Guiding Principles on Internal Displacement. New York, 1998. Disponível em: [http://www.unhcr.org/protection/idps/43ce1cff2/guiding-principles-internal-displacement.html\#]. Acesso em: 15 Mar 2018.

UNITED NATIONS HUMAN SETTLEMENTS PROGRAMME (UN-HABITAT). International guidelines on urban and territorial planning. Nairobi: UN-HABITAT, 2015.

SDG GOAL 11 MONITORING FRAMEWORK: A guide to assist national and local governments to monitor and report on SDG Goal 11 indicators. Nairobi: UN-HABITAT, 2016.

Streets as public spaces and drivers of urban prosperity. Nairobi: UN-HABITAT, 2013.

Sustainable urbanization in the Paris Agreement: Comparative review of Nationally Determined Contributions for urban content. Nairobi: UN HABITAT, 2017. 
UNITED NATIONS POPULATION FUND (UNFPA). Sustainable Development and Population Dynamics: Placing people at the center. 2013. Disponível em: [http://www.unfpa.org/press/sustainabledevelopment-and-population-dynamics-placing-people-centre]. Acesso em: 15 Mai 2018.

Sustainable Development and Population Dynamics: Placing people at the center. 2013. Disponível em: [http://www.unfpa.org/press/sustainable-development-and-population-dynamicsplacing-people-centre]. Acesso em: 15 Mai 2018.

VIVEKANADA, J. Climate and security in urban Spaces and the role migration plays. Disponível em: [http://www.transre.org/en/blog/climate-and-security-urban-spaces-migration/]. Acesso em: 15 Mar 2018.

WARN, E.; ADAMO, S. B. The impact of climate change: migration and cities in South America. World Meteorological Organization (WTO), Vol. 63(2), 2014.

WATERS, C.N.; ZALASIEWICZ, J.A.; WILLIAMS, M. An introduction to the Anthropocene: case for and against a new epoch. In: WATERS, C.N.; ZALASIEWICZ, J.A.; WILLIAMS, M. A Stratigraphical Basis for the Anthropocene. London, UK: Geological Society of London Special Publications, 2014.

XXV PRÊMIO JOVEM CIENTISTA. Impactos da mudanças climáticas nas cidades: Capítulo 07 - Caderno do Professor. Disponível em: [http://www.seduc.go.gov.br/intranet/portal/sistemas/not/files/...]. Acesso em: 05 Mai 2018.

Trabalho enviado em 1 de novembro de 2018

Aceito em 30 de setembro de 2019 